Article

\title{
Performance Evaluation of Residential Demand Response Based on a Modified Fuzzy VIKOR and Scalable Computing Method
}

\author{
Jun Dong, Rong Li * and Hui Huang
}

School of Economics and Management, North China Electric Power University, Beijing 102206, China; dongjun624@126.com (J.D.); hh@ncepu.edu.cn (H.H.)

* Correspondence: lirong_huadian@163.com; Tel.: +86-10-6177-3073

Received: 27 March 2018; Accepted: 26 April 2018; Published: 29 April 2018

\begin{abstract}
For better utilizing renewable energy resources and improving the sustainability of power systems, demand response is widely applied in China, especially in recent decades. Considering the massive potential flexible resources in the residential sector, demand response programs are able to achieve significant benefits. This paper proposes an effective performance evaluation framework for such programs aimed at residential customers. In general, the evaluation process will face multiple criteria and some uncertain factors. Therefore, we combine the multi-criteria decision making concept and fuzzy set theory to accomplish the model establishment. By introducing trapezoidal fuzzy numbers into the Vlsekriterijumska Optimizacijia I Kompromisno Resenje (VIKOR) method, the evaluation model can effectively deal with the subjection and fuzziness of experts' opinions. Furthermore, we ameliorate the criteria weight determination procedure of traditional models via combining the fuzzy Analytic Hierarchy Process and Shannon entropy method, which can incorporate objective information and subjective judgments. Finally, the proposed evaluation framework is verified by the empirical analysis of five demand response projects in Chinese residential areas. The results give a valid performance ranking of the five alternatives and indicate that more attention should be paid to the criteria affiliated with technology level and economy benefits. In addition, a series of sensitivity analyses are conducted to examine the validity and effectiveness of the established evaluation framework and results. The study improves traditional multi-criteria decision making method VIKOR by introducing trapezoidal fuzzy numbers and combination weighing technique, which can provide an effective mean for performance evaluation of residential demand response programs in a fuzzy environment.
\end{abstract}

Keywords: demand response; residential customers; fuzzy VIKOR; combination weight; trapezoidal fuzzy numbers; sensitivity analysis

\section{Introduction}

During the past decades, with the rapid population growth and accelerated industrialization and urbanization construction, the energy demand is increasing sharply in China [1]. Wide exploitation and utilization of fossil energy has caused more and more serious environmental issues, such as greenhouse effects and large scale fog and hazy weather [2]. To deal with the conflicts between environment protection and economy development, a safe, effective and sustainable energy system is necessary for China [3]. Increasing the proportion of renewable energy sources (RES) in electricity generation and developing smart grids [4], energy internet [5] and some other new concepts have raised more and more concerns of successive Chinese governments [6]. In this respect, demand response (DR) is often viewed as a particularly suitable and effective way of coping with potential imbalances in power 
systems caused by RES as well as one of the main components in smart grids and energy internet $[7,8]$. DR is a specific type of demand-side management, which is focus on the instantaneous adjustment of electricity consumption pattern of end users at a given time point [9]. The implementations of DR can be classified into two main types: dispatchable and non-dispatchable [10]. Dispatchable DR resources refer to direct remote control of interruptible electricity consumers to reduce or shift demand according to the grid's real-time operation [11]. Non-dispatchable DR is defined as consumers' initiative control of their own electricity demand based on price changes. In the non-dipatchable DR situation, end-users can choose to respond the price change or not [12]. DR programs can not only reduce peak loads and traditional power generation, but also handle the variability issue caused by RES power generation [13].

In the past, implementation experience of DR has mainly concentrated on the industrial and commercial sectors, where some programs achieved significant demand reduction [14]. For instance, in the FSC Group's investigation, non-residential DR programs implemented in California (USA). showed large aggregate load reduction in the industrial sector and substantial differences in business categories [15]. Some DR programs aimed at industrial or commercial customers in Korea [16], United Kingdom [17], Norway [18], Denmark [19], Germany [20], Italy [21] are reported as having achieved considerable contributions for power systems. In China, a few demand side management programs were firstly implemented in the 1990s. Then in 2010, the National Development and Reform Commission (NDRC) announced the "Electricity Demand-side Management Measures" mainly aimed at the industrial segment [22]. For further promoting demand side management (DSM) and DR application, in 2012, Suzhou, Beijing, Foshan, Tangshan and Shanghai were selected as related pilot cities [23]. Compared with rich experience in industrial and commercial sectors, the residential DR implementation in China is still at the initial stage. However, in recent years, there has been a growing interest in residential DR programs because of their enormous application potential. As reported, in 2012, the energy consumption in Chinese residential sector has accounted for $10.90 \%$ of the total energy use [24]. Because residential loads are flexible and have great potential to be adjusted, more DR programs aimed at residential customers should be designed and carried out to ensure a stable and sustainable electricity system. It is noteworthy that performing DR programs not only needs the support of advanced technologies and devices, but also a comprehensive evaluation framework for the program performance. To better give a valuable decision references, some researchers have conducted related assessments on DR implementation in different countries or regions. From the point view of economy, Siano assessed the benefits of DR programs conducted in the residential sector mainly from the aspects of cost measurement and energy savings [25]. Moghaddam established an economic model to analyse the change trend of residential demand elasticity when implementing DR programs [26]. From the power system perspective, Dupont analyzed the impact of flexible loads on the demand side and quantified the operational benefits of DR [27]. Besides their influence on economy and electric system operation, the environmental value of DR projects has also aroused much attention in the current development situation. Reduction of pollutant and $\mathrm{CO}_{2}$ emissions as well as increase of RES penetration rate have become the new focuses when promoting DR. Rodríguez-García established an economic evaluation model for DR programs in which $\mathrm{CO}_{2}$ emission reduction was transformed into an economic value according to emission factors and market price [28]. For the whole cost-minimization of the system, Behboodi thought the intra-hourly DR is much more helpful in promoting additional RES than inter-hourly DR [29]. Although the previous studies gave us much inspiration for DR performance evaluation, there still are some limitations and room for improvement. First of all, a completed measurement index hierarchy needs to be established which is not only limited to a certain aspect. Secondly, most of the calculation methods or evaluation indexes depend on the data acquisition, which increases the difficulty and uncertainty for DR implementation evaluation in reality. From a sustainable perspective, the index system should include economic, environmental and social dimensions [30]. Moreover, because the smart devices play an important role when implementing DR programs in residential consumers, the completed evaluation index system should consider the 
technical factors as well. Hence, the final evaluation indexes for residential DR performance should be composed of economic, environmental, social and technical criteria.

For an evaluation model, considering the performance of residential DR programs involves many aspects, a multiple criteria decision making (MCDM) approach is suitable to be applied in the evaluation procedure [31]. MCDM has found its grounding application in many projects and enterprises in recent decades. Various MCDM techniques and algorithms were proved to be effective in the performance evaluation, such as elimination and choice translating reality (ELECTER), analytical hierarchy process (AHP), weighted sum model, technique for order preference by similarity to ideal solutions (TOPSIS) and its modified framework VlseKriterijumska Optimizacija I Kompromisno Resenje (VIKOR) [32,33]. In the DSM and DR research field, MCDM approaches have also seen extensive use during the last few years. Sanjay [34] conducted an evaluation of DSM implementation strategies in India with an AHP method. Mokhtar [35] analyzed and gave a selection framework for DSM options employing a combination of the AHP-PROMETHEE and TOPSIS methods. However, due to some unavoidable vagueness and uncertainty existing in the evaluating process, traditional MCDM methods may have limitations to accurately express experts' opinions [36]. Therefore, some studies showed solicitude to express the human's subjective languages and judgments with imprecise numeric values. Lin [37] introduced fuzzy set theory into TOPSIS to expand the traditional MCDM approach in the fuzzy environment. Dong incorporated fuzzy set, AHP and VIKOR methods to evaluated DSM [38] and DR [39] programs implemented in the commercial sector. Nevertheless, to the best of the authors' knowledge, no fuzzy MCDM method application was found regarding the evaluation of residential DR performance.

For better evaluating the implementation situation of residential DR programs in reality, we organized the paper as follows: based on the previous researches, we established a comprehensive index system for residential DR programs and innovated the evaluation framework by integrating VIKOR, fuzzy set theory and combination weighting approaches. Specifically, we used trapezoidal fuzzy numbers (TrFNs) to express all the linguistic ratings from experts rather than often used triangular fuzzy numbers (TFNs). TrFN can encompass more uncertainty compared with TFN which is only a special case of $\operatorname{TrFN}$ [40]. Moreover, to improve the rationality of the weighting determination process in fuzzy VIKOR, a new weighting method combining fuzzy-AHP and Shannon Entropy approaches was introduced in the paper. Through the proposed evaluation framework and calculation results, we can clearly learn which alternative has the best performance or achieves the most benefits. The results can give some inspiration for the decision makers when conducted related programs and offer references for policies formulation.

The primary contributions of the paper are:

1. From a sustainability perspective, the comprehensive evaluation index system aimed at residential DR programs was formed. The four pillars of criteria including economy, environment, technology and society can reflect the implementation effect of DR programs especially in residential customers completely.

2. A modified decision making model with multi-criteria was proposed to appraise the implementation of residential DR projects. We introduced TrFNs into the VIKOR method and at the same time improved the weighting determination by applying the combination weighing method. In virtue of the fuzzy set theory and TrFNs, the established model has its advantages to capture and deal with the fuzziness of decision makers effectively. The combination weighting technique can obtain more information containing subjective judgements as well as objective data for all alternatives.

3. To further examine the robustness and effectiveness of the model, we performed a series of sensitivity analyses. By changing the weights of each criterion and the parameters in the model, we observed whether the fluctuation would affect final ranking results. This is the first study to compare the importance of residential DR evaluation criteria for performance ranking results. The findings can give significant references during decision making about DR implementation. 
The paper contains seven sections, and the remaining structure is as follows: Section 2 introduces the basic theory and methodology. The framework of the proposed model is given in Section 3. Then Section 4 chooses and describes the evaluation criteria for residential DR performance. The empirical analysis of five residential DR programs in Beijing is conducted based on the proposed framework in Section 5. Findings and discussion are given in Section 6. Finally, we draw the conclusions in Section 7.

\section{Methodology}

For better understanding the proposed evaluation framework, we briefly introduce some related mathematical methods, including fuzzy set theory, fuzzy-VIKOR, fuzzy-AHP and Shannon Entropy. The fuzzy set theory is the fundamental for fuzzy-VIKOR and fuzzy-AHP, and TrFN as one of its expression forms is applied to deal with the linguistic terms in the calculation process. In addition, the combination method of fuzzy-AHP and Shannon Entropy improves the traditional weighting process of the fuzzy-VIKOR method.

\subsection{Fuzzy Sets Theory}

In the real world, decision makers are always faced with some uncertainties or doubts. They may describe a judgment by some vague words. To solve the vagueness and ambiguity, Zadeh [41] introduced fuzzy sets theory in 1965 which improved the linguistic judgments expression of decision making. Then fuzzy sets are developed to resolve the problem of lacking precise description in criteria importance weights assigning and alternatives rating during MCDM issues. A fuzzy set is constituted of a series of functions denoting the membership degree of an element. The degree membership of every factor is able to be expressed by a real number between $[0,1]$. When the element belongs to the fuzzy set totally, the degree number is " 1 ". Analogously, " 0 " stands for the criterion not belonging to the set at all. A value among [0,1] means the element belongs to the set partly. Based on the fuzzy set theory, some linguistic expression like "excellent", "good", "ordinary", "inferior" can be turned into a battery of interval values.

Fuzzy membership function has several types. This paper uses TrFNs to deal with the linguistic term. A positive TrFN can be defined as a quaternion $\widetilde{A}=\left(a_{1}, a_{2}, a_{3}, a_{4}\right)$ that respectively represent minimum possible value, most promising interval value, and maximum possible value [42]. The membership function $\mu_{\widetilde{A}}(x)$ is represented as Equation (1):

$$
\mu_{\widetilde{A}}(x)=\left\{\begin{array}{cc}
\frac{x-a_{1}}{a_{2}-a_{1}}, & a_{1} \leq x \leq a_{2} \\
1, & a_{2} \leq x \leq a_{3} \\
\frac{x-a_{4}}{a_{3}-a_{4}}, & a_{3} \leq x \leq a_{4} \\
0, & \text { otherwise }
\end{array}\right.
$$

$\widetilde{A}=\left(a_{1}, a_{2}, a_{3}, a_{4}\right)$ and $\widetilde{B}=\left(b_{1}, b_{2}, b_{3}, b_{4}\right)$ are positive TrFNs, $r$ is a positive real number, some common rules of operation are as follows:

$$
\begin{gathered}
\widetilde{A} \oplus \widetilde{B}=\left(a_{1}+b_{1}, a_{2}+b_{2}, a_{3}+b_{3}, a_{4}+b_{4}\right) \\
\widetilde{A} \ominus \widetilde{B}=\left(a_{1}-b_{1}, a_{2}-b_{2}, a_{3}-b_{3}, a_{4}-b_{4}\right) \\
\widetilde{A} \otimes r \cong\left(a_{1} r, a_{2} r, a_{3} r, a_{4} r\right)
\end{gathered}
$$

Humans always give indistinct answers rather than precise numerical values during MCDM processes. Fuzzy set theory and qualitative linguistic values have more advantages to assess performances than traditional numerical methods in a fuzzy environment. Thus, traditional MCDM methods combined with fuzzy set theory get more application in recent years, like fuzzy-AHP, fuzzy-TOPSIS, fuzzy-VIKOR etc. For comparing alternatives and getting intuitive results, Central Value 
(CV) method is introduced to defuzzy the fuzzy number $\widetilde{A}[43,44]$. The best non-fuzzy performance (BNP) number $B(\widetilde{A})$ denotes the defuzzying result which can be obtained using Equation (5) as follows [45]:

$$
\operatorname{Defuzz}(\widetilde{A})=B(\widetilde{A})=\frac{a_{2}+a_{3}}{2}+\frac{\left(a_{4}-a_{2}\right)-\left(a_{2}-a_{1}\right)}{6}=\frac{a_{1}+2 a_{2}+2 a_{3}+a_{4}}{6}
$$

\subsection{Fuzzy VIKOR Method}

Opricovic [46] put forward the VIKOR method for multi-criteria decision making. Its central theory is to construct an aggregated function for calculating the distances between evaluation point and positive or negative ideal points. For the purpose of dealing with the subjectivity and non-determinacy during deciding procedure, the fuzzy set theory could be applied to traditional VIKOR. The fuzzy VIKOR is more reliable and rational at getting alternative rankings than the conventional method with respect to various criteria and complexed decision environment [47].

We suppose that there are $L$ decision makers who give rankings of $m$ alternatives based on $n$ criteria. Each alternative will be evaluated as regards the $n$ criteria. Because of vagueness existing in subjective assessments, Table 1 gives the comparisons between linguistic variables and corresponding fuzzy numbers for decision makers to measure the uncertainty. Let $\widetilde{x}_{i j}=\left(x_{i j 1}, x_{i j 2}, x_{i j 3}, x_{i j 4}\right)$ be the fuzzy rating, in which $i$ denotes the alternatives, $j$ stands for criteria and $l$ represents evaluators, $i=1$, $2, \ldots, m ; j=1,2, \ldots, n$ and $l=1,2, \ldots, L$.

Detailed calculation steps of the fuzzy VIKOR method are as follows:

Step 1: Set up the original matrix integrating fuzzy decisions.

These fuzzy ratings of alternatives in terms of each criterion are aggregated as:

$$
\widetilde{x}_{i j}=\left(x_{i j 1}, x_{i j 2}, x_{i j 3}, x_{i j 4}\right)
$$

where $x_{i j 1}=\min \left\{x_{i j 1}\right\}, x_{i j 2}=\frac{1}{L} \sum_{l=1}^{L} x_{i j l 2}, x_{i j 3}=\frac{1}{L} \sum_{l=1}^{L} x_{i j l 3}$, and $x_{i j 4}=\max \left\{x_{i j l 4}\right\}$.

Then the aggregated fuzzy ratings can be further integrated into a matrix $X$, as in Equation (7).

$$
X=\left[\begin{array}{cccc}
\widetilde{x}_{11} & \widetilde{x}_{12} & \cdots & \widetilde{x}_{1 n} \\
\widetilde{x}_{21} & \widetilde{x}_{22} & \cdots & \widetilde{x}_{2 n} \\
\vdots & \vdots & \ddots & \vdots \\
\widetilde{x}_{m 1} & \widetilde{x}_{m 2} & \cdots & \widetilde{x}_{m n}
\end{array}\right]
$$

Step 2: Normalize the original fuzzy decision matrix.

Given that the criteria may have differences in measuring dimension, it is essential to standardize the aggregated fuzzy ratings. Among the evaluation indexes, those criteria whose higher values are favorable, are benefit-type criteria and those criteria whose smaller values are desirable, are cost-type criteria. The criteria normalization in the paper is based on linear scaling transformation method [48]. The benefit-type criteria are divided by the maximum value in the decision matrix with Equation (8). For cost-type criteria, use the criterion value to divide minimum value with Equation (9) to accordance with benefit-type measuring means. $Y=\left[\widetilde{y}_{i j}\right]_{m \times n}$ represents a standardized fuzzy decision matrix. The normalization equations are shown as follows:

$$
\begin{aligned}
& \widetilde{y}_{i j}=\left(y_{i j 1}, y_{i j 2}, y_{i j 3}, y_{i j 4}\right)=\left(\frac{x_{i j 1}}{u_{i}^{+}}, \frac{x_{i j 2}}{u_{i}^{+}}, \frac{x_{i j 3}}{u_{i}^{+}}, \frac{x_{i j 4}}{u_{i}^{+}}\right) \text {and } u_{i}^{+}=\max _{j}\left\{x_{i j 4}\right\} \\
& \widetilde{y}_{i j}=\left(y_{i j 1}, y_{i j 2}, y_{i j 3}, y_{i j 4}\right)=\left(\frac{u_{i}^{-}}{x_{i j 1}}, \frac{u_{i}^{-}}{x_{i j 2}}, \frac{u_{i}^{-}}{x_{i j 3}}, \frac{u_{i}^{-}}{x_{i j 4}}\right) \text { and } u_{i}^{-}=\min _{j}\left\{x_{i j 1}\right\}
\end{aligned}
$$


Step 3: Define the fuzzy positive and negative ideal solutions with respect to each criterion.

The comparative sequences of fuzzy positive ideal solution $\widetilde{\mathrm{R}}_{j}^{+}$and negative ideal solution $\widetilde{\mathrm{R}}_{j}^{-}$for each criterion can be determined as:

$$
\widetilde{\mathrm{R}}_{j}^{+}=\left[\widetilde{\mathrm{y}}_{01}^{+}, \widetilde{\mathrm{y}}_{02}^{+}, \ldots \widetilde{\mathrm{y}}_{0 n}^{+}\right], \widetilde{\mathrm{R}}_{j}^{-}=\left[\widetilde{\mathrm{y}}_{01}^{-}, \widetilde{\mathrm{y}}_{02}^{-}, \ldots \widetilde{\mathrm{y}}_{0 n}^{-}\right]
$$

where $\widetilde{\mathrm{y}}_{0 j}^{+}=\max _{i}\left(\widetilde{\mathrm{y}}_{i j}\right), \widetilde{\mathrm{y}}_{0 j}^{-}=\max _{i}\left(\widetilde{\mathrm{y}}_{i j}\right), j=1,2, \ldots, n$.

Step 4: Defuzzify the trapezoidal fuzzy numbers with Equation (5) and compute the crisp value distances from the positive ideal solutions with Equation (11):

$$
d_{i j}=\frac{\operatorname{Defuzz}\left(\widetilde{\mathrm{R}}_{j}^{+}\right)-\operatorname{Defuzz}\left(\widetilde{\mathrm{y}}_{i j}\right)}{\operatorname{Defuzz}\left(\widetilde{\mathrm{R}}_{j}^{+}\right)-\operatorname{Defuzz}\left(\widetilde{\mathrm{R}}_{j}^{-}\right)}
$$

where $d_{i j}$ represents the normalized distance between alternative $i$ in related with criterion $j$ and the positive ideal solution $\widetilde{\mathrm{R}}_{j}^{+}$.

Step 5: Compute utility $S_{i}$ and regret value $R_{i}$ for each alternative:

$$
\begin{aligned}
& S_{i}=\sum_{j=1}^{n} w_{j} d_{i j} \\
& R_{i}=\max _{j} w_{j} d_{i j}
\end{aligned}
$$

where $w_{j}$ denotes the criterion weight of $j . S_{i}$ indicates the maximum of the overall utility. Smaller values of $S_{i}$ show larger overall benefits. $R_{i}$ stands for the dissatisfactory degree of individual criteria presentations. Lower values of $R_{i}$ indicate less individual regret.

Step 6: Measure the compromise index $Q_{i}$ :

$$
Q_{i}=\eta \frac{S_{i}-S^{-}}{S^{*}-S^{-}}+(1-\eta) \frac{R_{i}-R^{-}}{R^{*}-R^{-}}
$$

where $S^{-}=\min _{i} S_{i}, S^{*}=\max _{i} S_{i}, R^{-}=\min _{i} R_{i}$ and $R^{*}=\max _{i} R_{i} . \eta$ reflects the weight of maximum overall benefits and $1-\eta$ measures the importance of individual regret.

Step 7: Compare $S_{i}, R_{i}, Q_{i}$ and obtain the ranking results of alternatives.

According to the decreasing order of $Q_{i}$ values, rank all alternatives. An alternative is more optimal if its $Q_{i}$ value is lower. The new ranking of all alternatives is marked as $A^{(1)}, A^{(2)}, \ldots, A^{(\mathrm{m})}$. In addition, only when satisfying the following conditions, the alternative $A^{(1)}$ with a lowest $Q_{i}$ value is the first best.

Condition 1:

$$
Q\left(A^{(2)}\right)-Q\left(A^{(1)}\right) \geq \frac{1}{(m-1)}
$$

where $\mathrm{m}$ denotes the number of evaluation alternatives.

Condition 2:

$A^{(1)}$ should be the optimal alternative according to the $S_{i}$ or $R_{i}$ in a decreasing order.

\subsection{Combination Weight Technique}

In order to give more accurate weights in the calculation process of fuzzy VIKOR, it is recommended to apply a combination weight technique, including subjective and objective weighting 
determine methods. The subjective weights can be obtained by fuzzy-AHP method on the basis of expert comments. Shannon Entropy method will be used to calculate the objective weights according to performance data.

\subsubsection{Fuzzy-AHP Method}

The Analytic Hierarchy Process (AHP) was first proposed by Saay [49] and developed by Marsh and Moran [50] who applied the method to decision making problems and gave detailed steps. As an effective method for dealing with the MCDM problem, AHP can clarify complicated relationships of criteria and handle a complex problem by decomposing it into some relatively simple sub-problems. However, the conventional AHP has some shortcomings in coping with subjective and ambiguous perception of an exact number. Therefore, Buckley developed the fuzzy-AHP model to deal with the issue [51]. In virtue of linguistic variables, fuzzy-AHP has more advantages to compute criteria weights than traditional AHP during an uncertain decision making processes. Most fuzzy AHP application models often only use TFNs. Nevertheless, TrFNs could better capture the most possible situation when concerning much of uncertainty compared with TFNs. In the paper, TrFNs is used in fuzzy AHP to determine the criteria weights.

Table 1. Linguistic variables and fuzzy number comparison [50].

\begin{tabular}{cc}
\hline Linguistic Variables & TrFNs \\
\hline Very poor $(\mathrm{VP})$ & $(0,0,0.1,0.2)$ \\
Poor $(\mathrm{P})$ & $(0.1,0.2,0.2,0.3)$ \\
Medium poor $(\mathrm{MP})$ & $(0.2,0.3,0.4,0.5)$ \\
Fair $(\mathrm{F})$ & $(0.4,0.5,0.5,0.6)$ \\
Medium good (MG) & $(0.5,0.6,0.7,0.8)$ \\
Good (G) & $(0.7,0.8,1.0,1.0)$ \\
Very good (VG) & $(0.8,0.9,1.0,1.0)$ \\
\hline
\end{tabular}

Assume $C_{I}=\left\{C_{1}, C_{2}, \ldots, C_{N}\right\}$ is a set for main criteria, and $C_{i}=\left\{c_{1}, c_{2}, \ldots, c_{n}\right\}$ is for sub-criteria. A hierarchal structure needs to be built at first step, which contains three levels of evaluation goal, main criteria and sub-criteria, as presented in Figure 1. After establishing the structure, the pairwise comparison judgements with fuzzy numbers will be conducted by using linguistic terms according to Zheng [52], as shown in Table 2.

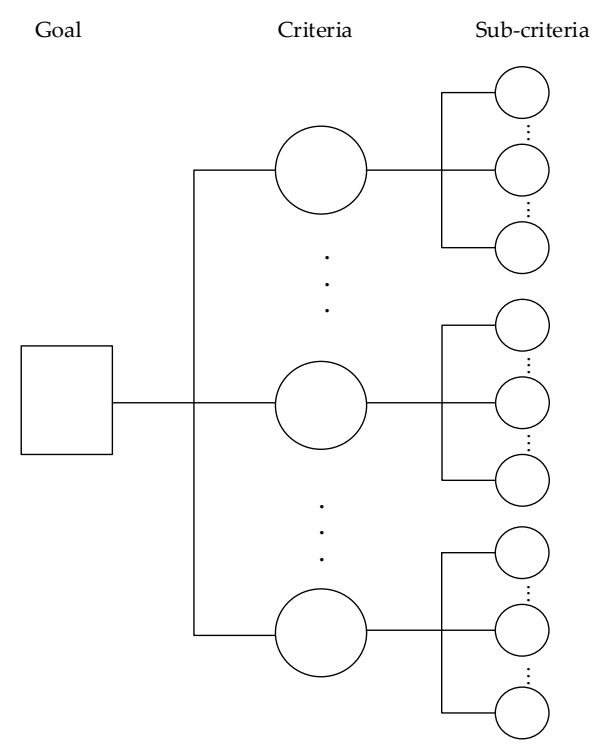

Figure 1. The hierarchical structure. 
Table 2. Linguistic terms and TrFN numbers comparison.

\begin{tabular}{ccl}
\hline Linguistic Variables & TFNs & \multicolumn{1}{c}{ Meaning } \\
\hline Equally important (EI) & $(1,1,1,1)$ & Criterion $i$ and $j$ are equally important \\
Weakly important (WI) & $(2,5 / 2,7 / 2,4)$ & Criterion $i$ is weakly more important than $j$ \\
Strongly important (SI) & $(4,9 / 2,11 / 2,6)$ & Criterion $i$ is strongly more important than $j$ \\
Very strongly important (VI) & $(6,13 / 2,15 / 2,8)$ & Criterion $i$ is very strongly more important than $j$ \\
Absolutely important (AI) & $(8,17 / 2,9,9)$ & Criterion $i$ is absolutely more important than $j$ \\
\hline
\end{tabular}

Based on the comparison judgments and TrFNs, the computing processes are as follows:

Step 1: Obtain the pair-wise comparison matrix.

Suppose that $\widetilde{a}_{I J}^{k}$ and $\widetilde{a}_{i j}^{k}$ respectively denote the pairwise comparison of main criteria and sub-criteria using TrFNs given by expert $k$ according to Table 2 . A single fuzzy judgement matrix $W^{k}$ of expert $k$ can be described as:

$$
W^{k}=\left|\begin{array}{cccc}
\tilde{a}_{11}^{k} & \tilde{a}_{12}^{k} & \cdots & \widetilde{a}_{1 n}^{k} \\
\tilde{a}_{21}^{k} & \widetilde{a}_{22}^{k} & \cdots & \widetilde{a}_{2 n}^{k} \\
\vdots & \vdots & \ddots & \vdots \\
\widetilde{a}_{n 1}^{k} & \widetilde{a}_{n 2}^{k} & \cdots & \widetilde{a}_{n n}^{k}
\end{array}\right|_{n \times n}
$$

In the above matrix, if $i>j, \tilde{a}_{i j}^{k}$ equals a TrFN according to the judgement of expert $k$; if $i=j$, $\tilde{a}_{i j}^{k}=(1,1,1,1)$; if $i<j, \tilde{a}_{i j}^{k}$ equals the reciprocal of the TrFN accordingly. For example, $\widetilde{a}_{11}^{k}=(1,1,1,1)$; if $\widetilde{a}_{21}^{k}=\left(4, \frac{9}{2}, \frac{11}{2}, 6\right), \widetilde{a}_{12}^{k}=\frac{1}{\widetilde{a}_{21}^{k}}=\left(\frac{1}{4}, \frac{2}{9}, \frac{2}{11}, \frac{1}{6}\right)$.

Step 2: Verify the consistency of judgement matrices.

For checking the consistency of judgement matrix intuitively, TrFNs should be converted into crisp numbers using Equation (5). The consistency of judgement matrix can be expressed by consistency ratio $(C R)$ which is calculated by Equations (17) and (18):

$$
\begin{gathered}
C R=\frac{C I}{R I} \\
C I=\frac{\lambda_{\max }-n}{n-1}
\end{gathered}
$$

where $C I$ is the consistency index and $R I$ is the random index as shown in Table $3 . \lambda_{\max }$ denotes the largest eigenvalue of fuzzy matrix, and $n$ is the matrix size.

Table 3. RI values for different matrix size.

\begin{tabular}{ccccccccccccccc}
\hline$n$ & 1,2 & 3 & 4 & 5 & 6 & 7 & 8 & 9 & 10 & 11 & 12 & 13 & 14 & 15 \\
$R I$ & 0 & 0.52 & 0.89 & 1.12 & 1.26 & 1.36 & 1.41 & 1.45 & 1.49 & 1.52 & 1.54 & 1.56 & 1.57 & 1.58 \\
\hline
\end{tabular}

As a rule, a fuzzy comparison matrix consistent threshold is set to 0.2 of $C R$ as the upper limit [53]. If $C R$ is less than 0.2 , we can consider the matrix is consistent.

Step 3: Form the aggregated fuzzy degree of each criterion.

Let $\bar{W}^{\text {main }}$ represent aggregated fuzzy judgement matrices of main criteria and $\bar{W}^{\text {sub }}$ represent the matrices of sub-criteria, shown as follows:

$$
\bar{W}^{\text {main }}=\left(\widetilde{a}_{I J}\right)_{N \times N}
$$




$$
\bar{W}^{s u b}=\left(\widetilde{a}_{i j}\right)_{n \times n}
$$

where $\widetilde{a}_{I J}=\frac{1}{K} \sum_{k=1}^{K} \tilde{a}_{I J}^{k}$ and $\widetilde{a}_{i j}=\frac{1}{K} \sum_{k=1}^{K} \widetilde{a}_{i j}^{k}$.

Let $H_{I}^{\text {main }}=\left(h_{I 1}^{m}, h_{I 2}^{m}, h_{I 3}^{m}, h_{I 4}^{m}\right)$ denote the fuzzy aggregated degree at the main criteria level, as:

$$
H_{I}^{\text {main }}=\sqrt[N]{\prod_{J}^{N} \tilde{a}_{I J}}
$$

where $h_{I 1}^{m} \sqrt[N]{\prod_{J=1}^{N} a_{I J 1}}, h_{I 2}^{m} \sqrt[N]{\prod_{J=1}^{N} a_{I J 2}}, h_{I 3}^{m} \sqrt[N]{\prod_{J=1}^{N} a_{I J 3}}, h_{I 4}^{m} \sqrt[N]{\prod_{J=1}^{N} a_{I J 4}}$.

Similarly, the fuzzy aggregated extent $H_{i}^{s u b}=\left(h_{i 1}^{s}, h_{i 2}^{s}, h_{i 3}^{s}, h_{i 4}^{s}\right)$ at the sub-criteria level is:

$$
H_{i}^{s u b}=\sqrt[N]{\prod_{j}^{N} \tilde{a}_{i j}}
$$

where $h_{I 1}^{s} \sqrt[N]{\prod_{j=1}^{N} a_{i j 1}}, h_{I 2}^{s} \sqrt[N]{\prod_{j=1}^{N} a_{i j 2}}, h_{I 3}^{s} \sqrt[N]{\prod_{j=1}^{N} a_{i j 3}}, h_{I 4}^{s} \sqrt[N]{\prod_{j=1}^{N} a_{i j 4}}$

Then use Equation (5) to transform $H_{I}^{\text {main }}$ and $H_{i}^{\text {sub }}$ to BNP values $B_{I}^{m}$ and $B_{i}^{s}$.

Step 4: Compute the main criteria and sub-criteria weights

Consequently, let $W_{I}^{\text {main }}$ and $w_{i}^{\text {sub }}$ represent the weight of main criterion and local sub-criterion respectively, as:

$$
\begin{aligned}
W_{I}^{\text {main }} & =\frac{B_{I}^{m}}{\sum_{I=1}^{N} B_{I}^{m}} \\
w_{i}^{s u b} & =\frac{B_{i}^{s}}{\sum_{i=1}^{N} B_{i}^{s}}
\end{aligned}
$$

Considering the hierarchy structure, normalize the global weight $W_{i}^{S G}$ for sub-criteria $i$ as:

$$
W_{i}^{S G}=W_{I}^{\text {main }} \times w_{i}^{\text {sub }}
$$

\subsubsection{Shannon Entropy Method for Objective Weights}

Entropy put forward by Shannon in 1947 [54] is a technique which can measure non-determinacy during information formulation. Thus, the method has its advantages when applied in the decision making process to obtain objective weights $[55,56]$. Shannon entropy is capable of assessing the importance of different criteria based on the quantity of information provided by data [57]. Suppose a MCDM problem has $m$ alternatives and $n$ criteria, then the decision matrix can be described as:

$$
X_{i j}=\left[\begin{array}{cccc}
x_{11} & x_{12} & \ldots & x_{1 n} \\
x_{21} & x_{22} & \ldots & x_{2 n} \\
\ldots & \ldots & \ldots & \ldots \\
x_{m 1} & x_{m 2} & \ldots & x_{m n}
\end{array}\right]
$$

The calculation steps of Shannon entropy are as follows:

Step 1: Normalize the decision matrix with Equation (27):

$$
P_{i j}=\frac{x_{i j}}{\sum_{i=1}^{m} x_{i j}}
$$

where $P_{i j}$ denotes the projection value of each criterion. 
Specially, if the decision making matrix is based on fuzzy numbers, we need to defuzzy the matrix before normalization.

Step 2: calculate the entropy value of each criterion with Equation (28):

$$
e_{j}=-k \sum_{i=1}^{m} P_{i j} \ln \left(P_{i j}\right)=-\frac{1}{\ln (m)} \sum_{i=1}^{m} P_{i j} \ln \left(P_{i j}\right)
$$

where $e_{j}$ is the entropy value for criteria $j ; k=(\ln (m))^{-1}$.

Step 3: Determine the divergence degree with Equation (29):

$$
\operatorname{div}_{j}=1-e_{j}
$$

where $d i v_{j}$ is the divergence degree of criterion $j$. A large value of $d i v_{j}$ indicates criterion $j$ is important. Step 4: obtain the objective weights for each criterion using Equation (30):

$$
w_{j}^{o}=\frac{d i v_{j}}{\sum_{i=1}^{m} d i v_{j}}
$$

where $w_{j}^{o}$ is the objective weight for criterion $j$.

\subsubsection{The Combination Method}

Based on the subjective and objective weights obtained above, the final combination weights of each criterion can be calculated using multiplicative synthesis, as: in:

$$
w_{j}^{c}=\frac{w_{j}^{s} \times w_{j}^{o}}{\sum_{j=1}^{n} w_{j}^{s} \times w_{j}^{o}}
$$

where, $w_{j}^{c}$ stands for combination weight of criterion $j . w_{j}^{s}$ denotes subjective weight of criterion $j$ using fuzzy AHP method. $w_{j}^{o}$ is the objective weight of criterion $j$ obtained from the Shannon entropy technique.

\section{Calculation Framework for the Proposed Model}

The proposed MCDM model to assess the DR project performance in residential areas is based on the modified fuzzy VIKOR and combination weights method. The detailed evaluation process consists of three phases, as shown in Figure 2:

Phase 1: Establish a comprehensive evaluation criteria system and identify the alternatives to be assessed.

In the first phase, experts from DR and relevant research fields are invited to participate in decision making groups. Based on the experts' opinions and industry characteristics, determine the criteria for evaluating the performance of residential DR programs according to relevant research literatures. Considering the reality, the alternatives to be assessed are selected.

Phase 2: Obtain the combining weights for each criterion in virtue of fuzzy AHP and Shannon entropy methods.

Based on the index system, determine the weights for criteria, aggregated by subjective and objective dimensions. In virtue of the fuzzy-AHP approach, experts' opinions can be processed for the subjective weights. Firstly, relevant experts need to assign linguistic ratings to each criterion 
according to Table 2. Then check each judgement matrix's consistency and aggregate the individual matrices. Finally, after computing the fuzzy synthetic extent values, we can obtain the subjective weights. On the other hand, the Shannon entropy method is applied to obtain the objective weights. During the calculation process, each alternative in regard to criteria will be allocated a TrFN which can be calculated based on the vague linguistic ratings according to the comparison Table 1 . Then defuzzify the decision matrix by CV method with Equation (6) and get the objective weights with Shannon entropy approach. Based on the results above, the last step to obtain the combining weights is using multiplicative synthesis to aggregate the subjective and objective weights.

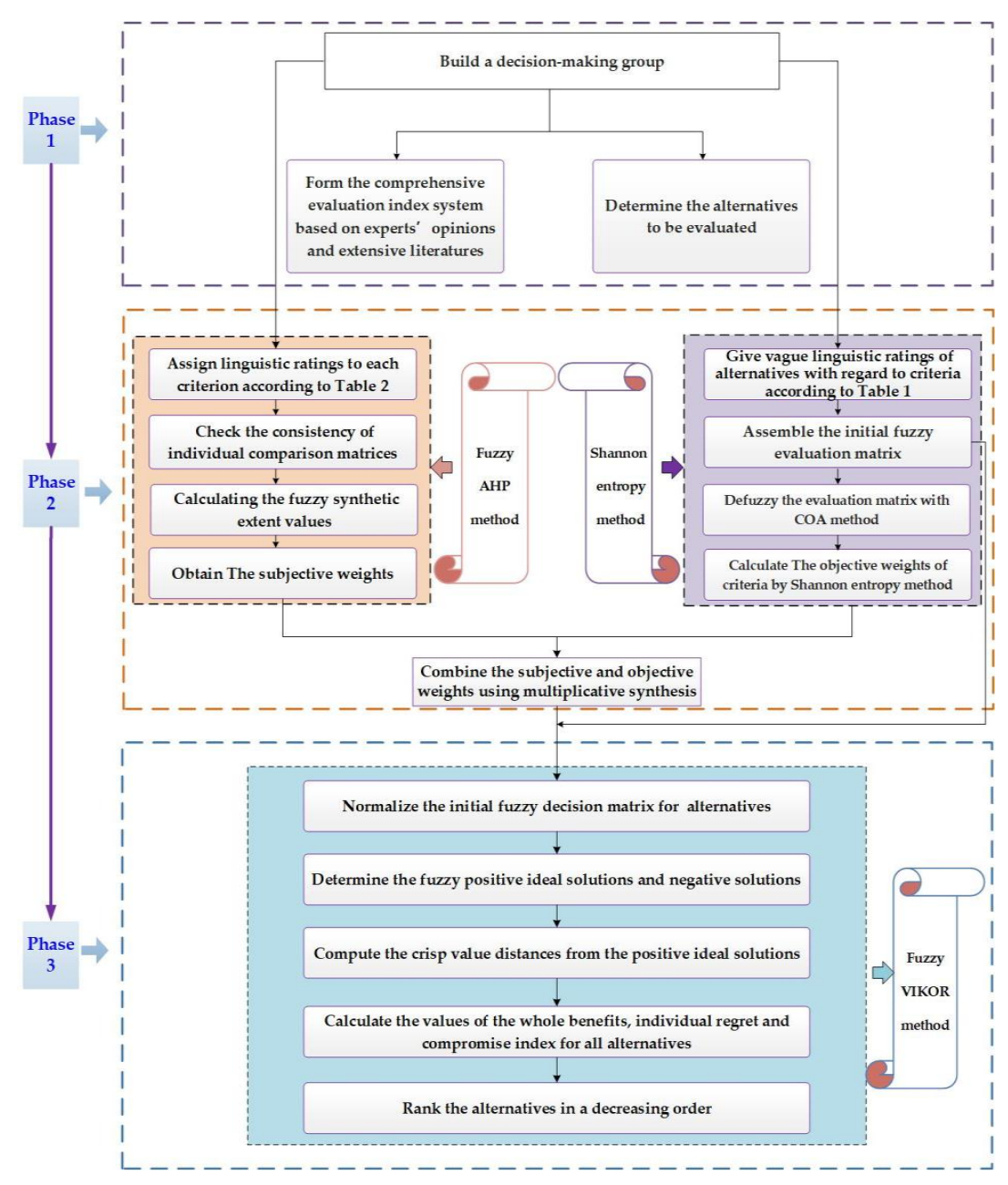

Figure 2. The research framework of the hybrid MCDM model for evaluating residential DR performance.

Phase 3: Evaluate the performance of residential DR alternatives by applying extended fuzzy VIKOR method.

In this phase, the first step is to standardize the initial fuzzy decision matrix of alternatives in phase 2. Then, determine a set of fuzzy positive and negative ideal solutions. Next, compute the crisp value distances from the positive ideal solutions of each alternative. Finally, rank the performances of alternatives following the order of $S_{i}, R_{i}$ and $Q_{i}$ from high to low.

The established MCDM frame in virtue of the modified fuzzy VIKOR and combination weighting method has three advantages as follows when applied to the comprehensive evaluation of DR performance. First of all, the framework can effectively capture and make use of the fuzziness of human judgements. Secondly, the combination weighting method has the outstanding capability to integrate more information from subjective weights and objective weights. Lastly, the modified 
fuzzy VIKOR with TrFNs and combination weights can efficiently tackle the vagueness and ambiguity of experts' judgements during the multi-criteria decision making process. Accordingly, the hybrid evaluation model is applicable and advantageous to deal with issues in reality.

\section{Establishing an Index System for Residential DR Performance Evaluation}

Evaluation criteria are very vital when evaluating residential DR programs. It is necessary to build a comprehensive evaluation index system to reflect the inherent characteristics of DR programs. Nonetheless, because DR programs are still at an early development stage in China, there is a lack of a consistent criteria system to appraise the residential DR performance. DR program application can not only provide short term benefits such as optimum allocation or operation of electrical power systems, but also achieve the long term goals of environmental protection or management [58]. From the perspective of sustainable development, we try to establish an evaluation index system considering economy, environment, technology and society factors. Furthermore, criteria affiliated with the above four dimensions are collected from experts and the literature, which are illustrated below. The completed evaluation indexes are shown in Figure 3.

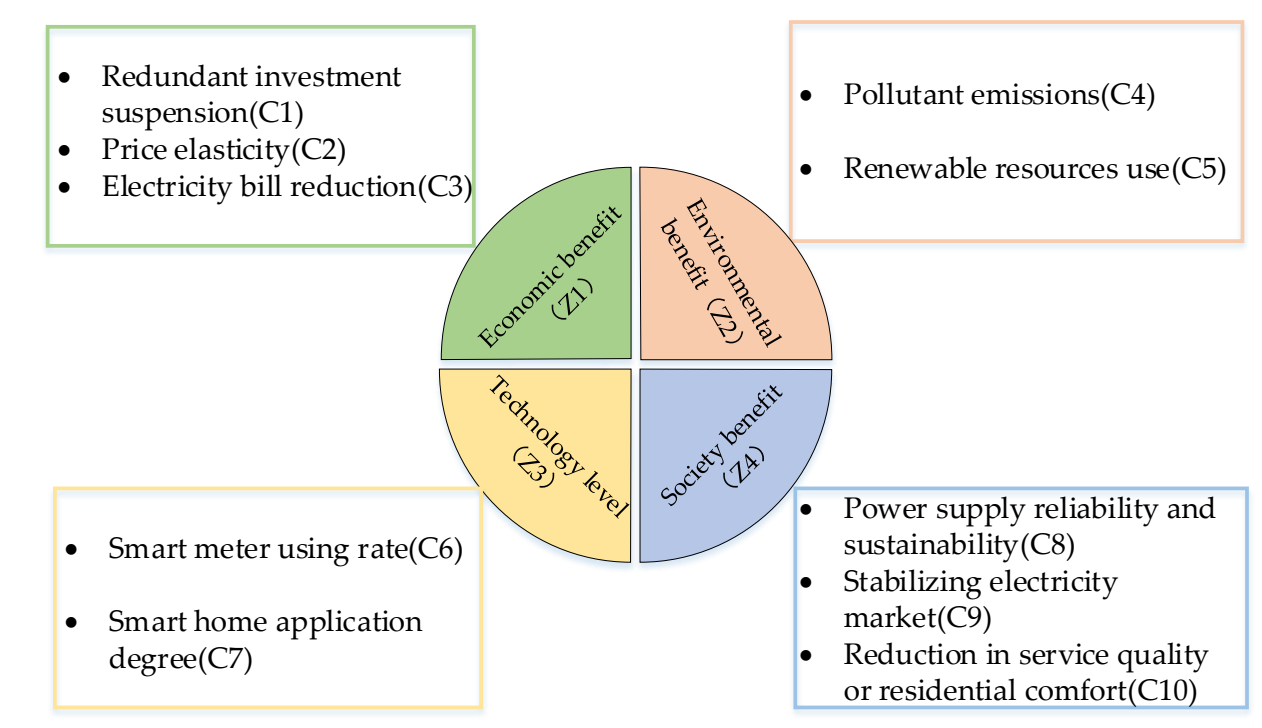

Figure 3. Comprehensive criteria for residential DR performance evaluation.

\subsection{Economic Benefit (Z1)}

DR programs applied in residential areas can obtain considerable economic benefits. The criteria associated with economy aspect for DR performance of residential users are summarized as below:

(1) Redundant investment suspension (C1): Refers to reducing the need to build extra generation or transmission infrastructure. DR programs can postpone or avoid some peaking plants or system capacity investment by adjusting residents' electricity usage habits [59,60].

(2) Price elasticity (C2): Refers to the elasticity of electricity demand with regard to electricity price changes in the residential sector. The elasticity can reflect the sensitivity of residents to electricity prices which can directly influence the performance of DR programs [60].

(3) Electricity bill reduction (C3): DR programs can guide residents to choose a most economical plan to use energy by combining different prices schemes. Through adjustment of energy use habits, users can also reduce their electricity bills [61].

\subsection{Environmental Benefit (Z2)}

The critical criteria affiliated with environmental benefits for DR performance evaluation are summarized as below: 
(1) Pollutant emission reduction (C4): Because DR can decrease peak loads and improve electric equipment utilization, it can be considered as a kind of clean energy resource. Thus, applying DR programs in residential areas can effectively reduce the emissions of harmful substances such as $\mathrm{SO}_{2}, \mathrm{NO}_{\mathrm{x}}$, and decrease greenhouse gas emissions [60].

(2) Renewable resources use (C5): As reserve resources, DR can stabilize renewable energy output, increase its consumptive ability, and promote renewable resource use [62].

\subsection{Technology Level (Z3)}

After stepping into an automation development stage, it is necessary for DR to apply new technologies as soon as possible [14]. The technology level refers to advanced terminal equipment or system application for DR programs. The critical criteria affiliated with technology level for DR performance evaluation are summarized as below:

(1) Smart meter use rate (C6): Smart meters can record electricity consumption in intervals of an hour or less and provide energy use information for monitoring centers, which can help residents and management departments to implement DR plans [61,63].

(2) Smart home application degree (C7): Smart homes include the control and automation of heating, lighting, air conditioning, ventilation and security. Smart home application can help customers find an optimized energy use scheme that maximizes their economic savings as well as fulfills DR program goals $[64,65]$.

\subsection{Societal Benefit (Z4)}

Developing DR programs can promote stable and sustainable development of society. The critical criteria affiliated with society benefits for DR performance evaluation are summarized as below:

(1) Power supply reliability and sustainability (C8): DR is an effective manner to improve electricity supply service. By reducing demand peaks and filling load valleys, it can alleviate electricity network stresses, and increase the supply reliability and sustainability of power supply $[60,66]$.

(2) Stabilizing electricity market (C9): DR program implementation can reduce spot price volatility, mitigate market power and increase the electricity market efficiency [67].

(3) Reduction in service quality or residential comfort (C10): Refers to when participating in the DR programs, residential comfort reduction or depreciation of the quality of the energy service provided [62].

Based on the description of the index system, we can know that except C10, the other criteria all pertain to benefit-type criteria where larger values represent better performance in the following evaluation process.

\section{Empirical Analysis}

\subsection{Case Statement}

Beijing, as one of the first DR pilot sites in China, has implemented a series of DR programs aimed at residential customers and has relatively rich experience in this field. Residential consumers or load integrators who participate in DR programs allow the temperature settings of air conditioners and brightness of lighting to be adjusted via intelligent sockets when it is necessary to reduce peak loads and ensure electric reliability. Based on this background, the proposed framework can be applied to the performance evaluation of DR programs for management promotion and sustainable development. We chose five residential DR alternatives $\mathrm{U} i(i=1,2, \ldots, 5)$ located in the Changping, Haidian, Chaoyang and Fengtai districts in Beijing as the empirical analysis cases; the location description is shown in Figure 4. The five alternatives are all residential areas, and their power supplier is a coal-fired power plant with 300 MW located in Hebei Province. U1 is an ordinary residential district build in 1998 
with a total of 800 households. Most of the inhabitants of U1 have been living there a long time and the intelligence degree of their devices is not very high. Demand response application is mainly aimed at the heating and air conditioning systems of each household. U2 is a newly-built high-end district with 1000 households and equipped with smart home systems. Its DR service areas are lighting, ventilation and air condition systems. U3 is an ordinary district with more than 20 years of construction history. The intelligence degree is close to that of U1, but its DR services are concentrated on lighting and air conditioning. U4 and U5 are both middle grade districts and their DR control implemented in lighting, ventilation and air conditioning systems. Because the five alternatives are at different levels of intelligence, the DR implementation types are various. U1 and U3 belong to direct load control program type, which means the program operator can remotely shut down the participators' electrical equipment (air conditioner or water heater) at short notice by installing load intervention devices. U2, U4 and U5 are price-based DR programs. Through smart home systems, the residents of U2, U4, and U5 can set up the power output of their electric equipment according to the time-of-use electricity rates. More detailed introduction of the five alternatives is presented in Table 4.

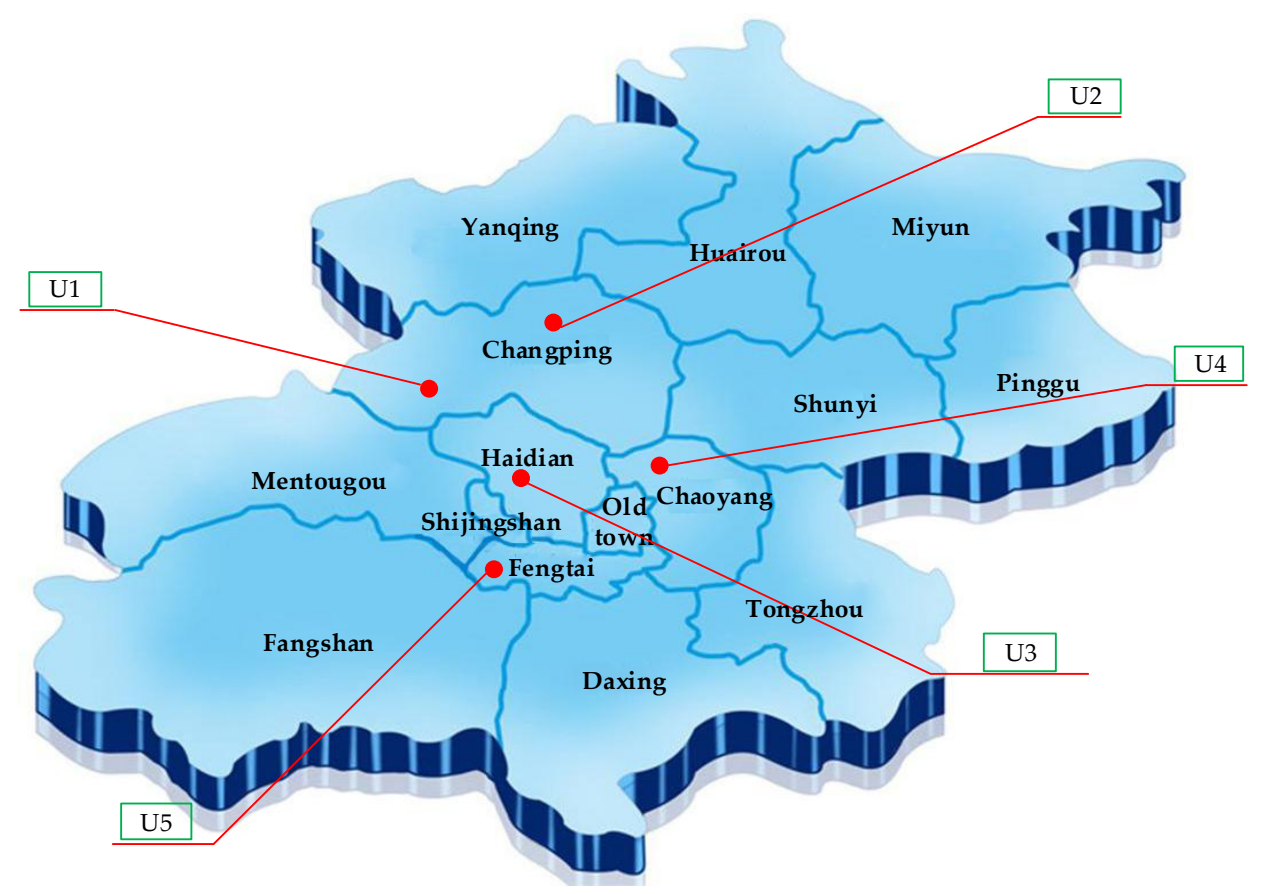

Figure 4. Location description of the selected alternatives in Beijing.

Table 4. The key features of the five DR projects in residential areas.

\begin{tabular}{cccccc}
\hline Alternative & U1 & U2 & U3 & U4 & U5 \\
\hline Category & Ordinary district & High-end district & Ordinary district & Middle grade district & Middle grade district \\
Year built & 1998 & 2009 & 1996 & 2003 & 1000 \\
Household number & 800 & 1000 & 750 & 1000 & 1200 \\
DR services & Heating and air & Lighting/Ventilation & Lighting and air & Lighting/Ventilation & Lighting/Ventilation \\
and air conditioning & and air conditioning \\
DR implementation & conditioning & and air conditioning & conditioning & 4 & 4 \\
years & 4 & 3 & 5 & & 4 \\
\hline
\end{tabular}

Four groups of experts in the DR research area are selected to make decisions. The characteristics of the experts are described in the Table 5. They are familiar with the DR programs and will give linguistic ratings of criteria and alternatives by mail or phone surveys. 
Table 5. Expert group characteristics description.

\begin{tabular}{ccccc}
\hline Items & Expert Group 1 (E1) & Expert Group 2 (E2) & Expert Group 3 (E3) & Expert Group 4 (E4) \\
\hline Affiliation & Research institution & Government & Electricity utilities & Building management \\
Experience (year) & $\geq 8$ & $\geq 7$ & $\geq 5$ & $\geq 5$ \\
Education level & Doctor & Master or above & Bachelor or above & Bachelor or above \\
Gender (Male/Female) & $2 / 3$ & $3 / 2$ & $4 / 1$ & $3 / 2$ \\
Age range & $36-57$ & $35-49$ & $29-45$ & $32-47$ \\
\hline
\end{tabular}

\subsection{Conbination Weights Calculation}

\subsubsection{Subjective Weight Calculation Based on Fuzzy AHP}

(1) Obtain fuzzy comparison matrices of all criteria importance.

The selected four groups of experts gave significance comparisons of the different layer criteria including main and sub-criteria based on linguistic ratings and TrFNs in Table 2. Then assemble the linguistic ratings of criteria importance as fuzzy comparison matrices and check their consistency by computing $C R$ values, the results shown in Table 6. As we can see, the $C R$ values are all below 0.2 . That means the experts' judgments are consistent and credible.

Table 6. CR values of main criteria and sub-criteria comparative matrices.

\begin{tabular}{cccccc}
\hline CR & Goal & Z1 & Z2 & Z3 & Z4 \\
\hline E1 & 0.000 & 0.000 & 0.000 & 0.000 & 0.037 \\
E2 & 0.016 & 0.176 & 0.000 & 0.000 & 0.130 \\
E3 & 0.043 & 0.000 & 0.000 & 0.000 & 0.130 \\
E4 & 0.072 & 0.037 & 0.000 & 0.000 & 0.122 \\
\hline
\end{tabular}

(2) Aggregate the information of the four group experts' comparison matrices to obtain an integrated fuzzy comparison matrix for each level criteria.

Assume that $\widetilde{A}_{i j}=\left(A_{i j 1}, A_{i j 2}, A_{i j 3}, A_{i j 4}\right)$ is a component in the integrated fuzzy comparison matrix. We give an instance to illustrate how $\widetilde{A}_{12}$ represents the importance comparison between the economic main criterion ( $Z 1)$ and environmental main criterion (Z2). The linguistic ratings given by the four expert groups are Z2 WI Z1, Z1 EI Z2, Z1 WI Z2 and Z1 WI Z2. They can be aggregated as:

$$
\begin{aligned}
& A_{121}=\frac{1}{4}\left(\frac{1}{2}+\frac{1}{2}+2+2\right)=1.25 \\
& A_{122}=\frac{1}{4}\left(\frac{2}{5}+\frac{2}{5}+\frac{5}{2}+\frac{5}{2}\right)=1.45 \\
& A_{123}=\frac{1}{4}\left(\frac{2}{7}+\frac{2}{7}+\frac{7}{2}+\frac{7}{2}\right)=1.89 \\
& A_{124}=\frac{1}{4}\left(\frac{1}{4}+\frac{1}{4}+4+4\right)=2.13
\end{aligned}
$$

Thus, $A_{12}=(1.25,1.45,1.89,2.13)$. Analogously, we can calculate the other criteria importance in each integrated fuzzy comparison matrix and the results are listed in Tables 7-11. 
Table 7. Integrated fuzzy comparison matrix for main-criteria weights.

\begin{tabular}{ccccc}
\hline Main-Criteria & Z1 & Z2 & Z3 & Z4 \\
\hline Z1 & $(1,1,1,1)$ & $(1.25,1.45,1.89,2.13)$ & $(1.81,2.06,2.55,2.79)$ & $(1.44,1.53,1.74,1.85)$ \\
Z2 & $(1.25,1.45,1.89,2.13)$ & $(1,1,1,1)$ & $(2.03,2.40,3.15,3.53)$ & $(1.06,1.18,1.42,1.54)$ \\
Z3 & $(1.44,1.53,1.74,1.85)$ & $(2.31,2.38,2.44,2.42)$ & $(1,1,1,1)$ & $(1.06,1.18,1.42,1.54)$ \\
Z4 & $(1.81,2.06,2.55,2.79)$ & $(1.63,1.73,1.95,2.06)$ & $(1.63,1.73,1.95,2.06)$ & $(1,1,1,1)$ \\
\hline
\end{tabular}

Table 8. Integrated fuzzy comparison matrix for Z1 sub-criteria weights.

\begin{tabular}{cccc}
\hline Sub-Criteria & C1 & C2 & C3 \\
\hline C1 & $(1,1,1,1)$ & $(1.63,1.86,2.34,2.58)$ & $(0.50,0.46,0.41,0.40)$ \\
C2 & $(2.19,2.41,2.87,3.10)$ & $(1,1,1,1)$ & $(0.92,1.01,1.23,1.34)$ \\
C3 & $(2.75,3.13,3.88,4.25)$ & $(2.38,2.60,3.07,3.31)$ & $(1,1,1,1)$ \\
\hline
\end{tabular}

Table 9. Integrated fuzzy comparison matrix for Z2 sub-criteria weights.

\begin{tabular}{ccc}
\hline Sub-Criteria & C4 & C5 \\
\hline C4 & $(1,1,1,1)$ & $(1.50,1.75,2.25,2.50)$ \\
C5 & $(0.75,0.70,0.64,0.63)$ & $(1,1,1,1)$ \\
\hline
\end{tabular}

Table 10. Integrated fuzzy comparison matrix for Z3 sub-criteria weights.

\begin{tabular}{ccc}
\hline Sub-Criteria & C6 & C7 \\
\hline C6 & $(1,1,1,1)$ & $(1.38,1.60,2.07,2.31)$ \\
C7 & $(1.00,1.08,1.27,1.38)$ & $(1,1,1,1)$ \\
\hline
\end{tabular}

Table 11. Integrated fuzzy comparison matrix for $\mathrm{Z} 4$ sub-criteria weights.

\begin{tabular}{cccc}
\hline Sub-Criteria & C8 & C9 & C10 \\
\hline C8 & $(1,1,1,1)$ & $(2.75,3.13,3.88,4.25)$ & $(2.13,2.48,3.20,3.56)$ \\
C9 & $(1.44,1.53,1.74,1.85)$ & $(1,1,1,1)$ & $(1.22,1.31,1.52,1.63)$ \\
C10 & $(0.81,0.88,1.06,1.17)$ & $(3.56,3.95,4.55,4.79)$ & $(1,1,1,1)$ \\
\hline
\end{tabular}

(3) Determine fuzzy aggregated extent and obtain the normalized subjective weight.

Through Equations (19)-(22), fuzzy aggregated extent values $H$ can be received, and furthermore transformed to the corresponding BNP values. Via Equation (25), the results of subjective weights $W_{i}^{S G}$ will also be obtained. The results are presented in Table 12.

Table 12. Fuzzy aggregated extent values and evaluation criteria weights.

\begin{tabular}{|c|c|c|c|c|c|c|}
\hline \multicolumn{3}{|c|}{ Main Criteria } & \multicolumn{4}{|c|}{ Sub-Criteria } \\
\hline & $H$ & $W_{I}^{\text {main }}$ & & $H$ & $w_{i}^{S u b}$ & $W_{i}^{S G}$ \\
\hline \multirow{3}{*}{$\mathrm{Z} 1$} & \multirow{3}{*}{$(0.81,1.14,2.10,2.75)$} & \multirow{3}{*}{0.253} & $\mathrm{C} 1$ & $(0.27,0.29,0.32,0.34)$ & 0.065 & 0.017 \\
\hline & & & $\mathrm{C} 2$ & $(0.67,0.81,1.18,1.39)$ & 0.215 & 0.054 \\
\hline & & & $\mathrm{C} 3$ & $(2.18,2.71,3.97,4.69)$ & 0.720 & 0.182 \\
\hline \multirow{2}{*}{$\mathrm{Z} 2$} & \multirow{2}{*}{$(0.67,1.03,2.12,2.89)$} & \multirow{2}{*}{0.248} & $\mathrm{C} 4$ & $(0.75,0.88,1.13,1.25)$ & 0.747 & 0.159 \\
\hline & & & $\mathrm{C} 5$ & $(0.38,0.35,0.35,0.32)$ & 0.253 & 0.089 \\
\hline \multirow{2}{*}{$\mathrm{Z3}$} & \multirow{2}{*}{$(0.88,1.08,1.51,1.73)$} & \multirow{2}{*}{0.196} & C6 & $(0.69,0.80,1.04,1.16)$ & 0.610 & 0.119 \\
\hline & & & $\mathrm{C} 7$ & $(0.50,0.54,0.63,0.69)$ & 0.390 & 0.076 \\
\hline \multirow{3}{*}{$\mathrm{Z} 4$} & \multirow{3}{*}{$(1.20,1.53,2.41,2.97)$} & \multirow{3}{*}{0.303} & $\mathrm{C} 8$ & $(1.95,2.58,4.13,5.05)$ & 0.610 & 0.185 \\
\hline & & & C9 & $(0.58,0.67,0.88,1.01)$ & 0.140 & 0.043 \\
\hline & & & $\mathrm{C} 10$ & $(0.96,1.15,1.61,1.86)$ & 0.250 & 0.076 \\
\hline
\end{tabular}




\subsubsection{Objective Weight Calculation Based on Shannon Entropy}

Based on the performance of five alternatives, the four group experts should give their linguistic evaluation according to Table 1 firstly. The experts' linguistic judgements of alternatives for each criterion is summarized in Table 13.

Table 13. Linguistic judgments of five alternatives for criteria performances.

\begin{tabular}{cccccccccccc}
\hline Alternatives & Expert Groups & C1 & C2 & C3 & C4 & C5 & C6 & C7 & C8 & C9 & C10 \\
\hline \multirow{4}{*}{ U1 } & E1 & F & F & F & MP & G & MP & G & F & G & F \\
& E2 & MP & MG & F & F & G & F & G & F & MG & MG \\
& E3 & F & F & MG & MP & MG & P & MG & MG & VG & G \\
& E4 & MP & MG & MG & F & MG & MP & MG & MG & MG & MG \\
\hline \multirow{4}{*}{ U2 } & E1 & MG & MG & F & F & G & F & MG & MG & VG & F \\
& E2 & G & G & MG & G & F & MG & MG & MG & G & MG \\
& E3 & MG & G & G & MG & F & G & F & G & G & MG \\
& E4 & G & MG & F & F & MG & G & MG & G & VG & G \\
\hline \multirow{4}{*}{ U3 } & E1 & VP & MG & MP & F & F & F & VP & MG & F & F \\
& E2 & P & F & MP & P & F & F & P & MG & F & P \\
& E3 & VP & F & F & VP & MP & P & VP & F & MP & MP \\
& E4 & P & VG & MP & F & MP & MP & P & F & MP & MP \\
\hline \multirow{4}{*}{ U4 } & E1 & MG & F & F & F & F & F & MG & MG & VG & F \\
& E2 & G & MG & MP & MG & MG & MG & F & MG & G & G \\
& E3 & MG & G & F & F & F & F & MG & VG & G & VG \\
& E4 & G & F & F & F & MP & P & F & G & MG & MG \\
\hline \multirow{2}{*}{ U5 } & E1 & MG & VP & P & F & F & F & MP & F & MP & F \\
& E2 & P & P & MP & F & MG & MP & MP & MP & P & F \\
& E3 & F & VP & MP & MG & MG & VP & F & MG & P & G \\
& E4 & MP & VP & F & MG & VP & MP & MP & F & P & MG \\
\hline
\end{tabular}

Then the TrFNs of five alternatives for ten criteria can be aggregated in Table 14 according to Equation (6). We take the TrFN of $\mathrm{U} 1$ with respect to criterion $\mathrm{C} 1$ for example to explain the calculation process:

$$
\begin{gathered}
X_{121}=\operatorname{MIN}(0.4,0.2,0.4,0.2)=0.2 \\
X_{122}=\frac{1}{4}(0.5+0.3+0.5+0.3)=0.4 \\
X_{123}=\frac{1}{4}(0.5+0.4+0.5+0.4)=0.45 \\
X_{121}=\operatorname{MAX}(0.6,0.5,0.6,0.5)=0.6
\end{gathered}
$$

Table 14. Fuzzy evaluation matrix of alternatives according to criteria performance.

\begin{tabular}{cccccc}
\hline Sub-Criteria & U1 & U2 & U3 & U4 & U5 \\
\hline C1 & $(0.2,0.4,0.45,0.6)$ & $(0.5,0.7,0.85,1)$ & $(0,0.1,0.15,0.3)$ & $(0.5,0.7,0.85,1)$ & $(0.1,0.4,0.45,0.8)$ \\
C2 & $(0.4,0.55,0.6,0.8)$ & $(0.5,0.7,0.85,1)$ & $(0.4,0.625,0.675,1)$ & $(0.4,0.6,0.675,1)$ & $(0,0.05,0.125,0.3)$ \\
C3 & $(0.4,0.55,0.6,0.8)$ & $(0.4,0.6,0.675,1)$ & $(0.2,0.35,0.425,0.6)$ & $(0.2,0.45,0.475,0.6)$ & $(0.1,0.325,0.375,0.6)$ \\
C4 & $(0.2,0.4,0.45,0.6)$ & $(0.4,0.6,0.675,1)$ & $(0,0.3,0.325,0.6)$ & $(0.4,0.525,0.55,0.8)$ & $(0.4,0.55,0.6,0.8)$ \\
C5 & $(0.5,0.7,0.85,1)$ & $(0.4,0.6,0.675,1)$ & $(0.2,0.4,0.45,0.6)$ & $(0.2,0.475,0.525,0.8)$ & $(0,0.425,0.5,0.8)$ \\
C6 & $(0.1,0.325,0.375,0.6)$ & $(0.4,0.675,0.8,1)$ & $(0.1,0.375,0.4,0.6)$ & $(0.1,0.45,0.475,0.8)$ & $(0,0.275,0.35,0.6)$ \\
C7 & $(0.5,0.7,0.85,1)$ & $(0.4,0.575,0.65,0.8)$ & $(0,0.1,0.15,0.3)$ & $(0.4,0.55,0.6,0.8)$ & $(0.2,0.35,0.425,0.6)$ \\
C8 & $(0.4,0.55,0.6,0.8)$ & $(0.5,0.7,0.85,1)$ & $(0.4,0.55,0.6,0.8)$ & $(0.5,0.725,0.85,1)$ & $(0.2,0.475,0.525,0.8)$ \\
C9 & $(0.5,0.725,0.85,1)$ & $(0.7,0.85,1,1)$ & $(0.2,0.4,0.45,0.6)$ & $(0.5,0.775,0.925,1)$ & $(0.1,0.225,0.25,0.5)$ \\
C10 & $(0.4,0.625,0.725,1)$ & $(0.4,0.625,0.725,1)$ & $(0.1,0.325,0.375,0.6)$ & $(0.4,0.7,0.8,1)$ & $(0.4,0.6,0.675,1)$ \\
\hline
\end{tabular}

With Equation (5), the BNP numbers matrix of fuzzy evaluation can be aggregated as in Table 15. 
Table 15. BNP numbers of the evaluation criteria.

\begin{tabular}{ccccccccccc}
\hline Alternatives & C1 & C2 & C3 & C4 & C5 & C6 & C7 & C8 & C9 & C10 \\
\hline U1 & 0.417 & 0.583 & 0.583 & 0.417 & 0.767 & 0.350 & 0.767 & 0.583 & 0.775 & 0.683 \\
U2 & 0.767 & 0.767 & 0.658 & 0.658 & 0.658 & 0.725 & 0.608 & 0.767 & 0.900 & 0.683 \\
U3 & 0.133 & 0.667 & 0.392 & 0.308 & 0.417 & 0.375 & 0.133 & 0.583 & 0.417 & 0.350 \\
U4 & 0.767 & 0.658 & 0.442 & 0.558 & 0.500 & 0.458 & 0.583 & 0.775 & 0.817 & 0.733 \\
U5 & 0.433 & 0.108 & 0.350 & 0.583 & 0.442 & 0.308 & 0.392 & 0.500 & 0.258 & 0.658 \\
\hline
\end{tabular}

Using Equations (27)-(30), the normalized decision matrix $P_{i j}$ and objective weights $w_{j}^{o}$ of the criteria in line with entropy method can be obtained, as shown in Table 16.

Table 16. $P_{i j}$ and evaluation criteria objective weights according to entropy method.

\begin{tabular}{ccccccccccc}
\hline $\boldsymbol{P}_{i j}$ & C1 & C2 & C3 & C4 & C5 & C6 & C7 & C8 & C9 & C10 \\
\hline $\mathrm{U} 1$ & 0.241 & 0.165 & 0.275 & 0.158 & 0.309 & 0.182 & 0.245 & 0.220 & 0.241 & 0.165 \\
$\mathrm{U} 2$ & 0.271 & 0.261 & 0.237 & 0.327 & 0.245 & 0.239 & 0.284 & 0.220 & 0.271 & 0.261 \\
$\mathrm{U} 3$ & 0.162 & 0.122 & 0.150 & 0.169 & 0.054 & 0.182 & 0.132 & 0.113 & 0.162 & 0.122 \\
$\mathrm{U} 4$ & 0.182 & 0.221 & 0.180 & 0.207 & 0.235 & 0.242 & 0.258 & 0.236 & 0.182 & 0.221 \\
$\mathrm{U} 5$ & 0.144 & 0.231 & 0.159 & 0.139 & 0.158 & 0.156 & 0.082 & 0.212 & 0.144 & 0.231 \\
$e_{j}$ & 0.982 & 0.980 & 0.982 & 0.968 & 0.930 & 0.991 & 0.946 & 0.983 & 0.982 & 0.980 \\
div $_{j}$ & 0.018 & 0.020 & 0.018 & 0.032 & 0.070 & 0.009 & 0.054 & 0.017 & 0.018 & 0.020 \\
$w_{j}^{o}$ & 0.046 & 0.052 & 0.045 & 0.082 & 0.180 & 0.023 & 0.137 & 0.044 & 0.046 & 0.052 \\
\hline
\end{tabular}

\subsubsection{Subjective and Objective Weights Combination}

Integrate the virtues of fuzzy AHP and Shannon Entropy to get the combination weights $w_{j}^{c}$ with Equation (31). The combination weights of each criterion are listed in the Table 17.

Table 17. Combination weights of the evaluation criteria.

\begin{tabular}{ccccccccccc}
\hline Weights & C1 & C2 & C3 & C4 & C5 & C6 & C7 & C8 & C9 & C10 \\
\hline$W_{i}^{S G}$ & 0.017 & 0.054 & 0.182 & 0.159 & 0.089 & 0.119 & 0.076 & 0.185 & 0.043 & 0.076 \\
$w_{j}^{o}$ & 0.205 & 0.186 & 0.046 & 0.052 & 0.045 & 0.082 & 0.18 & 0.023 & 0.137 & 0.044 \\
$w_{j}^{c}$ & 0.043 & 0.143 & 0.114 & 0.114 & 0.057 & 0.143 & 0.200 & 0.057 & 0.086 & 0.043 \\
\hline
\end{tabular}

\subsection{Residential DR Performance Evaluation Based on Fuzzy VIKOR}

Step 1: Standardize the fuzzy evaluation matrix shown in Table 14 with Equations (8) and (9). For benefit-type criteria $\mathrm{C} 1, \mathrm{C} 2, \mathrm{C} 3, \mathrm{C} 4, \mathrm{C} 5, \mathrm{C} 6, \mathrm{C} 7, \mathrm{C} 8$ and $\mathrm{C} 9$, they are divided by the maximum value in the fuzzy evaluation matrix respectively with Equation (8); and for cost-type criterion C10, divide the minimum value by C10 value with Equation (9). The normalization results are presented in Table 18.

Table 18. Standardization for fuzzy evaluation matrix of five alternatives.

\begin{tabular}{cccccc}
\hline Sub-Criteria & U1 & U2 & U3 & U4 & U5 \\
\hline C1 & $(0.2,0.4,0.45,0.6)$ & $(0.5,0.7,0.85,1)$ & $(0,0.1,0.15,0.3)$ & $(0.5,0.7,0.85,1)$ & $(0.1,0.4,0.45,0.8)$ \\
C2 & $(0.4,0.55,0.6,0.8)$ & $(0.5,0.7,0.85,1)$ & $(0.4,0.625,0.675,1)$ & $(0.4,0.6,0.675,1)$ & $(0,0.05,0.125,0.3)$ \\
C3 & $(0.4,0.55,0.6,0.8)$ & $(0.4,0.6,0.675,1)$ & $(0.2,0.35,0.425,0.6)$ & $(0.2,0.45,0.475,0.6)$ & $(0.1,0.325,0.375,0.6)$ \\
C4 & $(0.2,0.4,0.45,0.6)$ & $(0.4,0.6,0.675,1)$ & $(0,0.3,0.325,0.6)$ & $(0.4,0.525,0.55,0.8)$ & $(0.4,0.55,0.6,0.8)$ \\
C5 & $(0.5,0.7,0.85,1)$ & $(0.4,0.6,0.675,1)$ & $(0.2,0.4,0.45,0.6)$ & $(0.2,0.475,0.525,0.8)$ & $(0,0.425,0.5,0.8)$ \\
C6 & $(0.1,0.325,0.375,0.6)$ & $(0.4,0.675,0.8,1)$ & $(0.1,0.375,0.4,0.6)$ & $(0.1,0.45,0.475,0.8)$ & $(0,0.275,0.35,0.6)$ \\
C7 & $(0.5,0.7,0.85,1)$ & $(0.4,0.575,0.65,0.8)$ & $(0,0.1,0.15,0.3)$ & $(0.4,0.55,0.6,0.8)$ & $(0.2,0.35,0.425,0.6)$ \\
C8 & $(0.4,0.55,0.6,0.8)$ & $(0.5,0.7,0.85,1)$ & $(0.4,0.55,0.6,0.8)$ & $(0.5,0.725,0.85,1)$ & $(0.2,0.475,0.525,0.8)$ \\
C9 & $(0.5,0.725,0.85,1)$ & $(0.7,0.85,1,1)$ & $(0.2,0.4,0.45,0.6)$ & $(0.5,0.775,0.925,1)$ & $(0.1,0.225,0.25,0.5)$ \\
C10 & $(0.25,0.16,0.138,0.1)$ & $(0.25,0.16,0.138,0.1)$ & $(1,0.308,0.267,0.167)$ & $(0.25,0.143,0.125,0.1)$ & $(0.25,0.167,0.148,0.1)$ \\
\hline
\end{tabular}


Step 2: Define the series of positive ideal solutions $\widetilde{\mathrm{R}}_{j}^{+}$and negative ideal solutions $\widetilde{\mathrm{R}}_{j}^{-}$involved with evaluation criteria by Equation (10), presented in Table 19.

Table 19. Fuzzy ideal solutions for evaluation criteria.

\begin{tabular}{ccc}
\hline Sub-Criteria & $\widetilde{\mathbf{R}}_{j}^{+}$ & $\widetilde{\mathbf{R}}_{j}^{-}$ \\
\hline C1 & $(0.5,0.7,0.85,1)$ & $(0,0.1,0.15,0.3)$ \\
C2 & $(0.5,0.7,0.85,1)$ & $(0,0.05,0.125,0.3)$ \\
C3 & $(0.4,0.6,0.675,1)$ & $(0.1,0.325,0.375,0.6)$ \\
C4 & $(0.4,0.6,0.675,1)$ & $(0,0.3,0.325,0.6)$ \\
C5 & $(0.5,0.7,0.85,1)$ & $(0,0.4,0.45,0.6)$ \\
C6 & $(0.4,0.675,0.8,1)$ & $(0,0.275,0.35,0.6)$ \\
C7 & $(0.5,0.7,0.85,1)$ & $(0,0.1,0.15,0.3)$ \\
C8 & $(0.5,0.725,0.85,1)$ & $(0.2,0.475,0.525,0.8)$ \\
C9 & $(0.7,0.85,1,1)$ & $(0.1,0.225,0.25,0.5)$ \\
C10 & $(1,0.308,0.267,0.167)$ & $(0.25,0.143,0.125,0.1)$ \\
\hline
\end{tabular}

Step 3: Defuzzify the fuzzy numbers in Tables 18 and 19, and the results are shown in Table 20. Then calculate the crisp value distances from the positive ideal solutions of five alternatives with respect to each criteria by Equation (11), as listed in Table 21.

Table 20. The BNP numbers for the standardization evaluation matrix and ideal solutions.

\begin{tabular}{cccccccc}
\hline Sub-Criteria & U1 & U2 & U3 & U4 & U5 & $\widetilde{\mathbf{R}}_{j}^{+}$ & $\widetilde{\mathbf{R}}_{j}^{-}$ \\
\hline C1 & 0.417 & 0.767 & 0.133 & 0.767 & 0.433 & 0.767 & 0.133 \\
C2 & 0.583 & 0.767 & 0.667 & 0.658 & 0.108 & 0.767 & 0.108 \\
C3 & 0.583 & 0.658 & 0.392 & 0.442 & 0.350 & 0.658 & 0.350 \\
C4 & 0.417 & 0.658 & 0.308 & 0.558 & 0.583 & 0.658 & 0.308 \\
C5 & 0.767 & 0.658 & 0.417 & 0.500 & 0.442 & 0.767 & 0.383 \\
C6 & 0.350 & 0.725 & 0.375 & 0.458 & 0.308 & 0.725 & 0.308 \\
C7 & 0.767 & 0.608 & 0.133 & 0.583 & 0.392 & 0.767 & 0.133 \\
C8 & 0.583 & 0.767 & 0.583 & 0.775 & 0.500 & 0.775 & 0.500 \\
C9 & 0.775 & 0.900 & 0.417 & 0.817 & 0.258 & 0.900 & 0.258 \\
C10 & 0.158 & 0.158 & 0.386 & 0.148 & 0.163 & 0.386 & 0.148 \\
\hline
\end{tabular}

Table 21. The standardized distances for five alternatives on each criterion.

\begin{tabular}{cccccc}
\hline Sub-Criteria & U1 & U2 & U3 & U4 & U5 \\
\hline C1 & 0.553 & 0.000 & 1.000 & 0.000 & 0.526 \\
C2 & 0.278 & 0.000 & 0.152 & 0.165 & 1.000 \\
C3 & 0.243 & 0.000 & 0.865 & 0.703 & 1.000 \\
C4 & 0.690 & 0.000 & 1.000 & 0.286 & 0.214 \\
C5 & 0.000 & 0.283 & 0.913 & 0.696 & 0.848 \\
C6 & 0.900 & 0.000 & 0.840 & 0.640 & 1.000 \\
C7 & 0.000 & 0.250 & 1.000 & 0.289 & 0.592 \\
C8 & 0.697 & 0.030 & 0.697 & 0.000 & 1.000 \\
C9 & 0.195 & 0.000 & 0.753 & 0.130 & 1.000 \\
C10 & 0.958 & 0.958 & 0.000 & 1.000 & 0.934 \\
\hline
\end{tabular}

Step 4: Compute the utility value $S_{i}$, regret value $R_{i}$ and compromise index $Q_{i}$, and give the ranks of all alternatives.

Based on Equations (12)-(14), the values of $S_{i}, R_{i}$ and $Q_{i}$ can be obtained as shown in Table 22. Then rank alternatives by the decreasing order of $S_{i}, R_{i}$ and $Q_{i}$, with $\eta=0.5$, and check the two conditions about the two preferred alternatives ranking. The final performance ranking is $\mathrm{U} 2>\mathrm{U} 4>$ $\mathrm{U} 1>\mathrm{U} 5>\mathrm{U} 3$, as shown in Table 23. 
Table 22. Calculation results of $S_{i}, R_{i}$ and $Q_{i}$.

\begin{tabular}{cccccc}
\hline Items & U1 & U2 & U3 & U4 & U5 \\
\hline$S_{i}$ & 0.396 & 0.109 & 0.754 & 0.380 & 0.797 \\
$R_{i}$ & 0.129 & 0.050 & 0.200 & 0.091 & 0.143 \\
$Q_{i}$ & 0.471 & 0 & 0.969 & 0.335 & 0.810 \\
\hline
\end{tabular}

Table 23. The performance orders of all the alternatives.

\begin{tabular}{cccccc}
\hline Items & U1 & U2 & U3 & U4 & U5 \\
\hline$S_{i}$ & 3 & 1 & 4 & 2 & 5 \\
$R_{i}$ & 3 & 1 & 5 & 2 & 4 \\
$Q_{i}$ & 3 & 1 & 5 & 2 & 4 \\
\hline
\end{tabular}

\section{Findings and Discussion}

The performances of five residential DR programs are ranked with the method proposed in this paper. Based on the $Q_{i}$ values from low to high, we can sort the performance as the order of U2, U4, U1, U5, U3. U2 as the optimal program is followed by U4 and U1. From the results we can see that the proposed research framework has its advantages to select a best alternative and give rankings with reference value for decision makers. To further check the effectiveness of the modified fuzzy VIKOR, we compare the evaluation results with traditional weighting procedure results. Moreover, a series of sensitivity analyses are performed in this section for verifying the model steadiness and robustness.

The traditional fuzzy VIKOR is based on one subjective or objective weighting methods, which may ignore some important information. Table 24 shows the comparison results of fuzzy VIKOR with different weighting procedures including fuzzy AHP, entropy and combination weighting method. The evaluation ranks of five alternatives with entropy weighting method and the proposed combination weighting method are coincident. However, in the entropy weighting situation, the $Q_{i}$ values of the first two alternatives U2 and U4 is too close, which doesn't satisfy the selection Condition 1 (Equation (15)). Therefore, we can only think U2 and U4 are both optimal alternatives. In the proposed model, the combination weighing method tackles the problem effectively by integrating more information from subjective and objective aspects.

Table 24. The performance ranks of five alternatives using different weighting methods.

\begin{tabular}{ccccccc}
\hline Alternatives & $\begin{array}{c}\text { Fuzzy AHP } \\
\left(Q_{i} \text { Value }\right)\end{array}$ & Rank & $\begin{array}{c}\text { Entropy }\left(Q_{i}\right. \\
\text { Value })\end{array}$ & Rank & $\begin{array}{c}\text { Combination } \\
\text { Weighting }\left(\boldsymbol{Q}_{\boldsymbol{i}} \text { Value }\right)\end{array}$ & Rank \\
\hline $\mathrm{U} 1$ & 0.519 & 3 & 0.413 & 3 & 0.471 & 3 \\
$\mathrm{U} 2$ & 0 & 1 & 0 & 1 & 0 & 1 \\
$\mathrm{U} 3$ & 0.843 & 4 & 0.967 & 5 & 0.970 & 5 \\
$\mathrm{U} 4$ & 0.462 & 2 & 0.152 & 2 & 0.335 & 2 \\
U5 & 1 & 5 & 0.941 & 4 & 0.810 & 4 \\
\hline
\end{tabular}

Based on the comparison of different weighting methods applied in fuzzy VIKOR, we can find that the combination weighting has its advantages during MCDM. The proposed model can avoid some uncertainty caused by subjective or objective factors and give a more comprehensive evaluation result. Focusing on the above cases, Table 17 presents the initial combination weights allocation for ten sub-criteria. C7, C6 and C2 had the first three weights allocation. That implies C6 and C7, affiliated with technology level of terminal monitoring and control equipment, play an important role in the residential DR programs. Moreover, sub-criterion C2 affiliated with price elasticity also has relative great influence to the DR implementation. As far as we know, DR is still in a starting phase in China, especially in the residential area. Thus, the application of intelligent devices and technology in homes 
and economic incentives may promote residential DR programs more smoothly. However, with the maturity and extended application of DR in China, the weights of evaluation criteria may fluctuate accordingly. For possessing a profound understanding of the assessment results and check the ranking rationality, we conduct a series of sensitive analyses for criteria weights. Ten sub-criteria involved with the four evaluation aspects reduce their weights by $10 \%, 20 \%, 30 \%, 40 \%, 50 \%$ and increase $10 \%, 20 \%$, $30 \%, 40 \%, 50 \%$ than basic weights. Table 17 gives the basic weights.

In the respect of the economic benefits criteria weights change, no matter how sub-criterion $\mathrm{C} 1$ changes, the $Q_{i}$ values of the five alternatives have little fluctuation (Figure 5). With the increase of C2, the $Q_{i}$ values of $\mathrm{U} 4$ and $\mathrm{U} 5$ show swings and even a reversal of ranking. As for $\mathrm{C} 3$, its weight increase the influence on $Q_{i}$ of $\mathrm{U} 4$ and $\mathrm{U} 5$ more obviously. Therefore, $\mathrm{C} 2$ and $\mathrm{C} 3$ are the sensitive factors, but no matter how the weights change, the optimal alternatives are still $\mathrm{U} 2$ and $\mathrm{U} 4$.

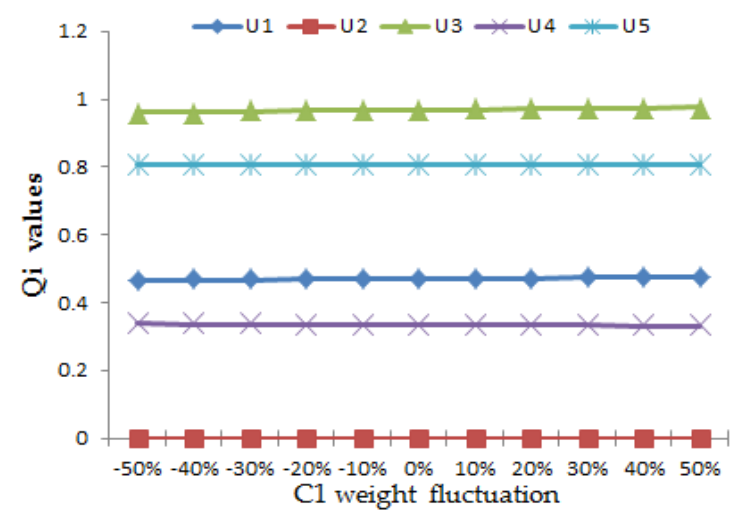

(a)

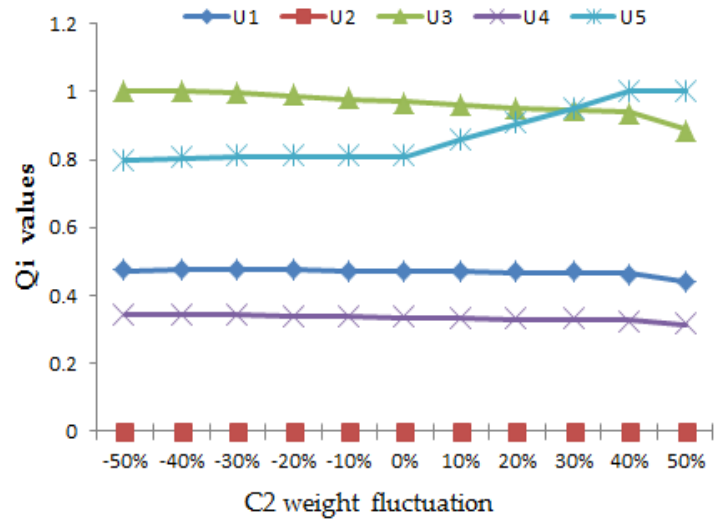

(b)

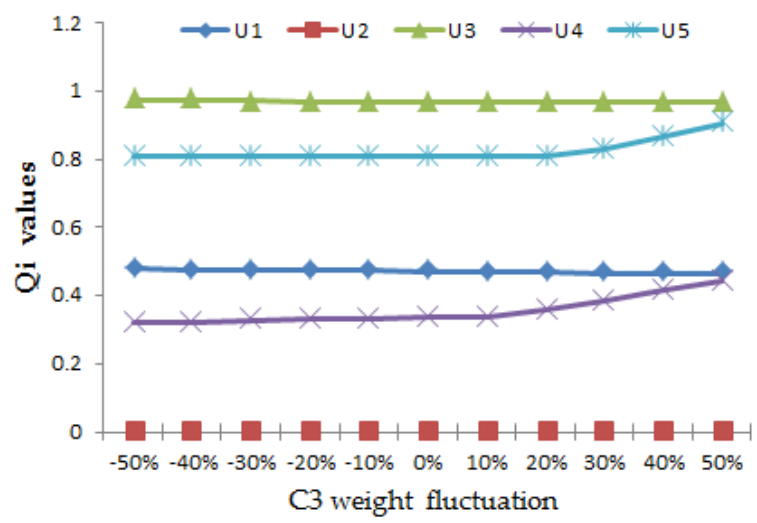

(c)

Figure 5. Weight sensitivity analysis for economic benefits criteria. (a) Weight sensitivity analysis for sub-criterion C1. (b) Weight sensitivity analysis for sub-criterion C2. (c) Weight sensitivity analysis for sub-criterion $\mathrm{C} 1$.

For the sub-criteria affiliated with environmental benefits aspect, the $Q_{i}$ values of five alternatives remain stable when corresponding weights changing, shown as Figure 6, which means $C 4$ and $C 7$ are stable criteria.

The weight sensitivity analysis for sub-criteria C6 and C7 in the technology main aspect is presented in Figure 7. As C6 and C7 are more important, the $Q_{i}$ values of U1, U3, U4 and U5 fluctuate strongly with the changing weights. We can see that except for $\mathrm{U} 2$, the other alternatives are sensitive to the technology level criteria. Although C6 and C7 weights may affect $Q_{i}$ values obviously, the top three alternatives are still $\mathrm{U} 2, \mathrm{U} 4$ and $\mathrm{U} 1$. 


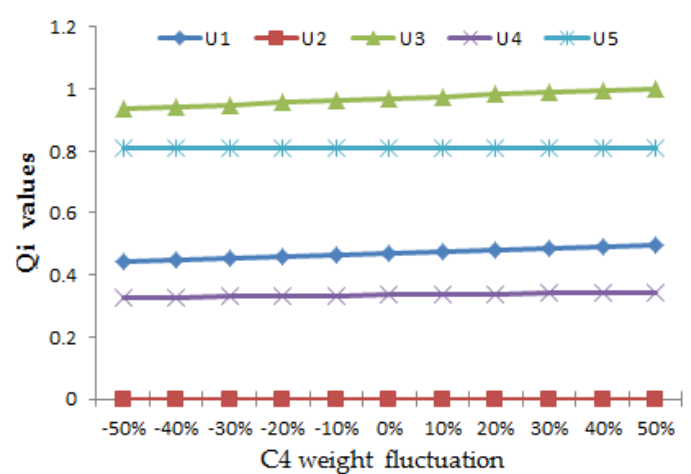

(a)

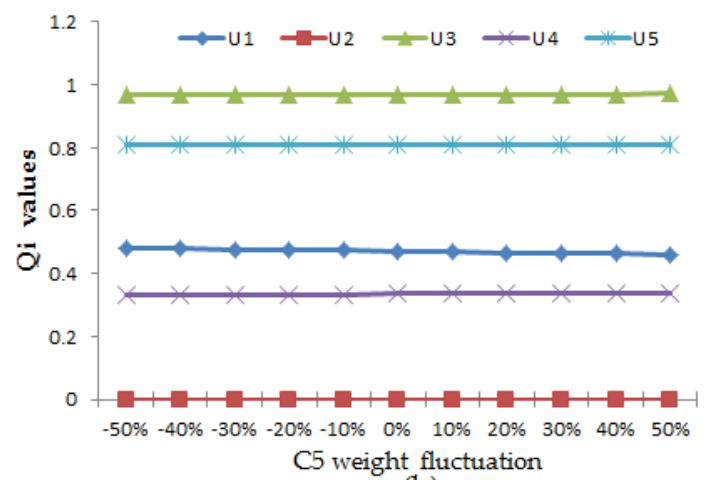

(b)

Figure 6. Weight sensitivity analysis for environmental benefits criteria. (a) Weight sensitivity analysis for sub-criterion C4. (b) Weight sensitivity analysis for sub-criterion C5.

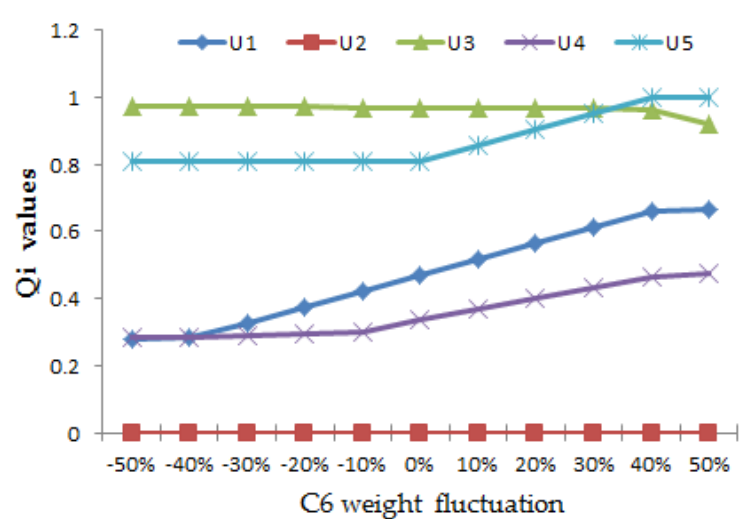

(a)

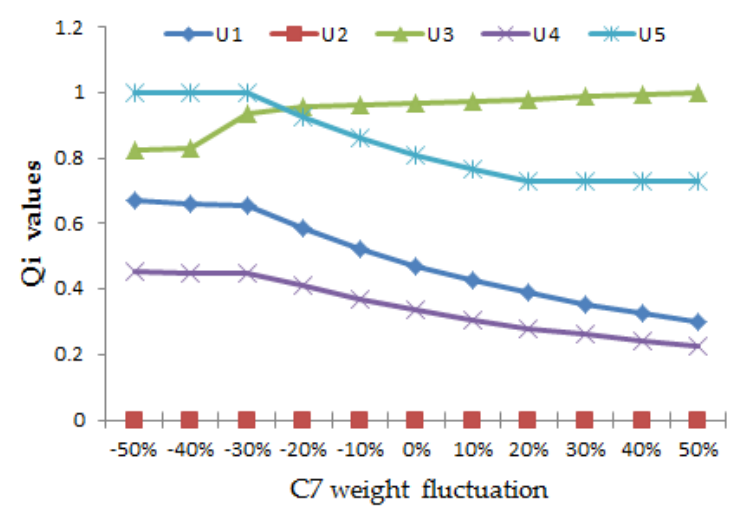

(b)

Figure 7. Weight sensitivity analysis for technology level criteria. (a) Weight sensitivity analysis for sub-criterion C6. (b) Weight sensitivity analysis for sub-criterion C7.

Figure 8 presents the case in which the weights of sub-criteria affiliated with social benefits aspect fluctuate up and down. The results indicate that C8, C9 and C10 are not the sensitive criteria in the evaluation process.

After the sensitivity analysis of criteria weights, for further examining the robustness and rationality of the evaluation framework, we conduct another sensitivity analysis for parameter $\eta$, which represents the weight of maximum group benefits in the fuzzy VIKOR method. The $\eta$ value is changed from 0.0 to 1.0 by steps of 0.1 to disclose the influence of ultimate order. The analysis conclusion is presented graphically in the Figure 9 and the alternatives final evaluation rankings are shown in the Figure 10. The best option is still U2 followed by U4 and U1.

Above all, the series of sensitivity studies prove that the evaluation results given by the established method are reliable and effective. It verifies the modified fuzzy VIKOR and combination weighting method is robust and valid to deal with a MCDM problem. 


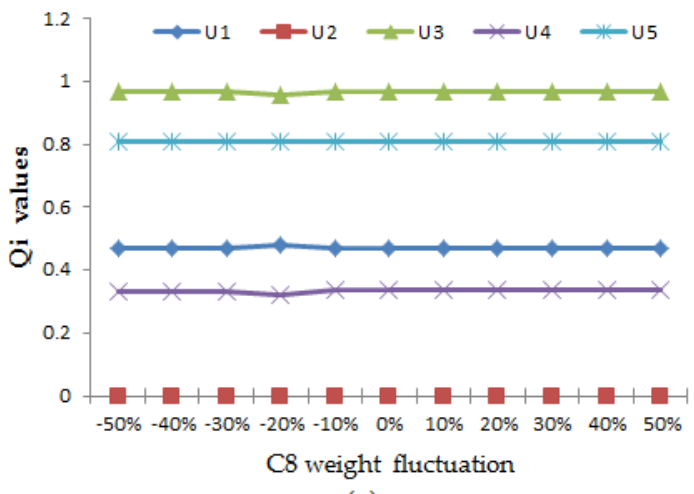

(a)

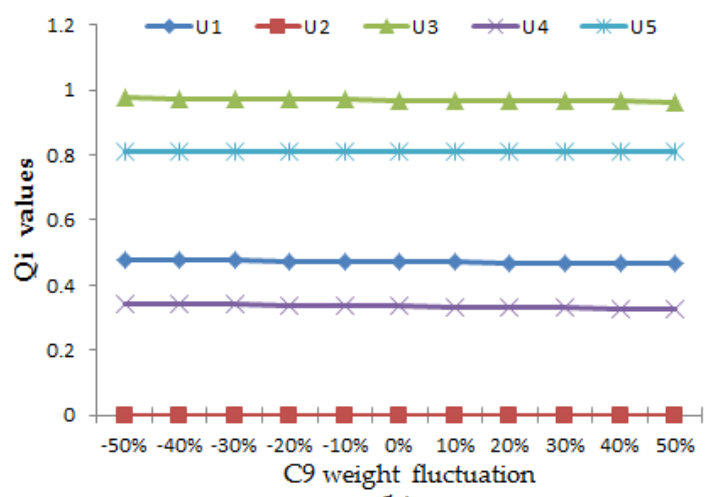

(b)

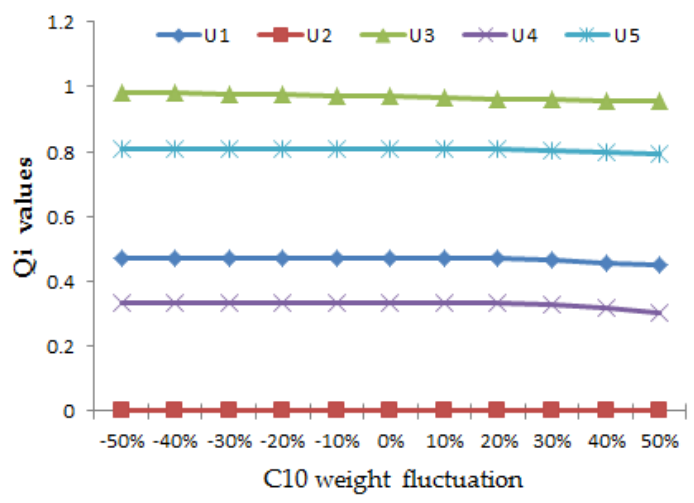

(c)

Figure 8. Weight sensitivity analysis for social benefits criteria. (a) Weight sensitivity analysis for sub-criterion C8. (b) Weight sensitivity analysis for sub-criterion C9. (c) Weight sensitivity analysis for sub-criterion $\mathrm{C} 10$.

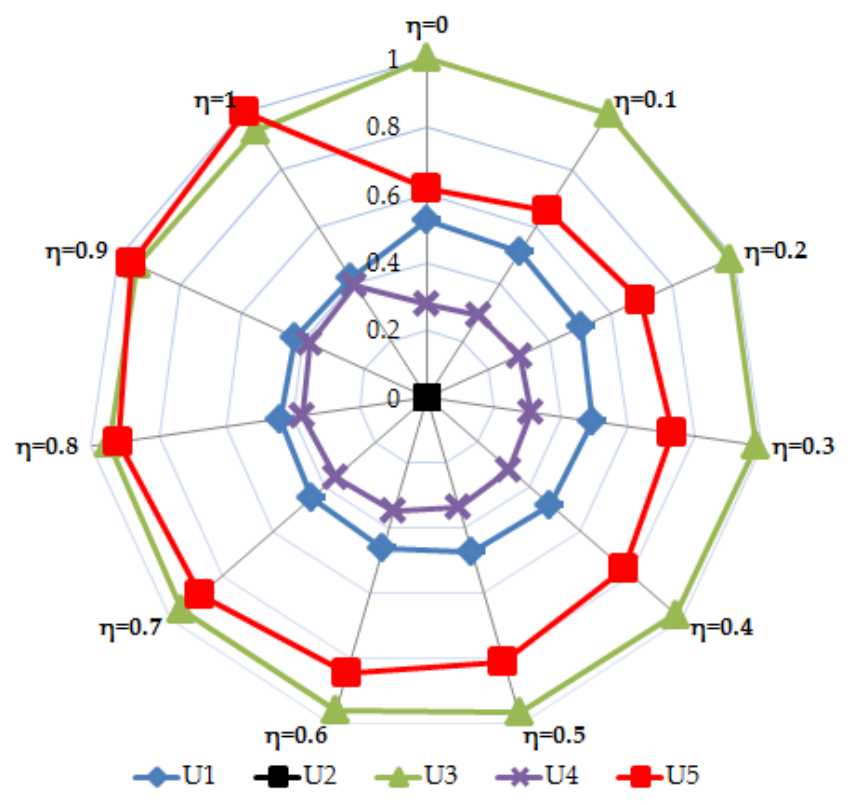

Figure 9. Parameter sensitivity analysis for $\eta$. 


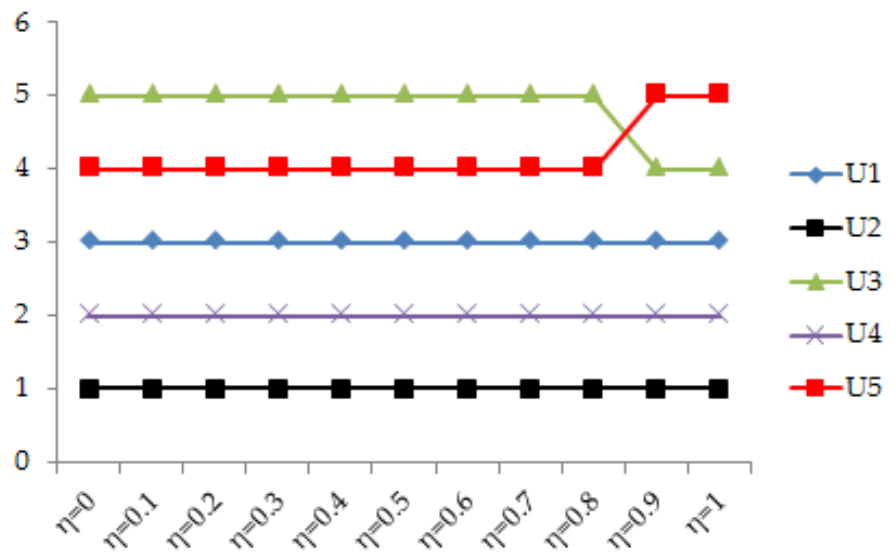

Figure 10. Alternatives final rankings of $\eta$ sensitivity analysis.

\section{Conclusions}

For the purpose of evaluating DR programs in the residential area, a hybrid framework is proposed in the paper. We can select optimal alternatives and promote the management of residential DR programs in virtue of the method. Based on the sustainable development perspective, an index system containing economy, environment, technology and society aspects is established for program performance evaluation. Then, to deal with the vagueness of experts during decision making process, the fuzzy VIKOR method with TrFNs is applied to give a comprehensive assessment result. The method has advantages in grasping the fuzziness information and coping with uncertainty of subjective judgements. Moreover, the paper modified the fuzzy VIKOR by introducing a combination weighting technique, in which fuzzy AHP and Shannon entropy methods played their own function in obtaining the subjective and objective weights. Compared with the traditional weighting procedure in fuzzy VIKOR, the proposed combination weighting method can integrate more information and give more rational weight allocation. The compound framework has clear calculation procedures and is proven reliable and effective in the empirical analysis. In the case study, sub-criteria C6, C7 and C2 affiliated with technology and economy dimensions garnered more attention from experts. To confirm the robustness and reliability of the model and rankings, we conduct a set of sensitivity analyses. The results indicate that however the ten sub-criteria weights and $\eta$ value adjust, the optimal alternatives are always $\mathrm{U} 2$ and $\mathrm{U} 4$ at the first and second preference respectively.

Although the hybrid approach is proven effective and suitable to deal with multi-criteria decision making issues, there still are some limitations to be improved. Since the index system is determined according to some research references and experts' opinions, as the development situation for DR programs changes, the evaluation criteria need to be updated in a timely way. Thus, it is necessary to perform the calculation procedures again based on the new index system. Moreover, from a methodological perspective, we will check the proposed framework by comparing with other approaches in a further study.

Author Contributions: Jun Dong and Rong Li conceived and designed the research method framework; Hui Huang performed the empirical analysis, Rong Li analyzed the empirical results and wrote the paper.

Acknowledgments: This study is supported by the Fundamental Research Funds for the Central Universities under Grant No. 2017XS095.

Conflicts of Interest: The authors declare no conflict of interest.

\section{References}

1. Dong, J.; Xue, G.; Li, R. Demand response in China: Regulations, pilot projects and recommendations-A review. Renew. Sustain. Energy Rev. 2016, 59, 13-27. [CrossRef] 
2. Zhao, X.; Luo, D. Driving force of rising renewable energy in China: Environment, regulation and employment. Renew. Sustain. Energy Rev. 2017, 68, 48-56. [CrossRef]

3. Yang, C.; Meng, C.; Zhou, K. Residential electricity pricing in China: The context of price-based demand response. Renew. Sustain. Energy Rev. 2017, 81, 2870-2878. [CrossRef]

4. Aghajani, G.R.; Shayanfar, H.A.; Shayeghi, H. Demand side management in a smart micro-grid in the presence of renewable generation and demand response. Energy 2017, 126, 622-637. [CrossRef]

5. Jiye, W.; Kun, M.; Junwei, C.; Zhihua, C.; Lingchao, G.; Chuang, L. Information technology for energy internet: A survey. J. Comput. Res. Dev. 2015, 52, 1109-1126.

6. Sun, Q.; Teng, F.; Zhang, H. Construction of dynamic coordinated optimization control system for energy internet. Proc. CSEE 2015, 35, 3667-3677.

7. Good, N.; Ellis, K.A.; Mancarella, P. Review and classification of barriers and enablers of demand response in the smart grid. Renew. Sustain. Energy Rev. 2017, 72, 57-72. [CrossRef]

8. Sun, Q.; Han, R.; Zhang, H.; Zhou, J.; Guerrero, J.M. A multiagent-based consensus algorithm for distributed coordinated control of distributed generators in the energy internet. IEEE Trans. Smart Grid 2015, 6, 3006-3019. [CrossRef]

9. Boßmann, T.; Eser, E.J. Model-based assessment of demand-response measures-Acomprehensive literature review. Renew. Sustain. Energy Rev. 2016, 57, 1637-1656. [CrossRef]

10. Mitra, S.; Grossmann, I.E.; Pinto, J.M.; Arora, N. Optimal production planning under time-sensitive electricity prices for continuous power-intensive processes. Comput. Chem. Eng. 2012, 38, 171-184. [CrossRef]

11. Yang, C.J. Opportunities and barriers to demand response in China. Resour. Conserv. Recycl. 2015, 121, 51-55. [CrossRef]

12. Procter, R.J. Integrating time-differentiated rates, demand response, and smart grid to manage power system costs. Electr. J. 2013, 26, 50-60. [CrossRef]

13. Pinson, P.; Madsen, H. Benefits and challenges of electrical demand response: A critical review. Renew. Sustain. Energy Rev. 2014, 39, 686-699.

14. Paterakis, N.G.; Erdinç, O.; Catalão, J.P.S. An overview of Demand Response: Key-elements and international experience. Renew. Sustain. Energy Rev. 2017, 69, 871-891. [CrossRef]

15. Bode, J.; Churchwell, C.; George, S.; Sullivan, F. California Statewide Non-Residential Critical Peak Pricing Evaluation; Freeman, Sullivan \& Co. (FSC): San Francisco, CA, USA, 2013.

16. Jang, D.; Eom, J.; Kim, M.G.; Rho, J.J. Demand responses of Korean commercial and industrial businesses to critical peak pricing of electricity. J. Clean. Prod. 2015, 90, 275-290. [CrossRef]

17. Liu, Y. Demand response and energy efficiency in the capacity resource procurement: Case studies of forward capacity markets in ISO New England, PJM and Great Britain. Energy Policy 2017, 100, 271-282. [CrossRef]

18. Faruqui, A.; Harris, D.; Hledik, R. Unlocking the $€ 53$ billion savings from smart meters in the EU: How increasing the adoption of dynamic tariffs could make or break the EU's smart grid investment. Energy Policy 2010, 38, 6222-6231. [CrossRef]

19. Clausen, A.; Maersk-Moeller, H.M.; Soerensen, J.C.; Joergensen, B.N.; Kjaer, K.H.; Ottosen, C.O. Integrating commercial greenhouses in the smart grid with demand response based control of supplemental lighting. In Proceedings of the International Conference Industrial Technology Management Science (ITMS 2015), Tianjin, China, 27-25 March 2015; pp. 199-213.

20. Aghaei, J.; Alizadeh, M.I. Demand response in smart electricity grids equipped with renewable energy sources: A review. Renew. Sustain. Energy Rev. 2013, 18, 64-72. [CrossRef]

21. Shoreh, M.H.; Siano, P.; Shafie-khah, M.; Loia, V.; Catalão, J.P. A survey of industrial applications of demand response. Electr. Power Syst. Res. 2016, 141, 31-49. [CrossRef]

22. Zhang, S.; Jiao, Y.; Chen, W. Demand-side management (DSM) in the context of China's on-going power sector reform. Energy Policy 2017, 100, 1-8. [CrossRef]

23. Guo, P.; Li, V.O.K.; Lam, J.C.K. Smart demand response in China: Challenges and drivers. Energy Policy 2017, 107, 1-10. [CrossRef]

24. Nie, H.; Kemp, R.; Xu, J.; Vasseur, V.; Fan, Y. Drivers of urban and rural residential energy consumption in China from the perspectives of climate and economic effects. J. Clean. Prod. 2017, 172, 2954-2963. [CrossRef]

25. Siano, P.; Sarno, D. Assessing the benefits of residential demand response in a real time distribution energy market. Appl. Energy 2016, 161, 533-551. [CrossRef] 
26. Moghaddam, M.P.; Abdollahi, A.; Rashidinejad, M. Flexible demand response programs modeling in competitive electricity markets. Appl. Energy 2011, 88, 3257-3269. [CrossRef]

27. Dupont, B.; Dietrich, K.; De Jonghe, C.; Ramos, A.; Belmans, R. Impact of residential demand response on power system operation: A Belgian case study. Appl. Energy 2014, 122, 1-10. [CrossRef]

28. Rodríguez-García, J.; Álvarez-Bel, C.; Carbonell-Carretero, J.F.; Alcázar-Ortega, M.; Peñalvo-López, E. A novel tool for the evaluation and assessment of demand response activities in the industrial sector. Energy 2016, 113, 1136-1146. [CrossRef]

29. Behboodi, S.; Chassin, D.P.; Crawford, C.; Djilali, N. Renewable resources portfolio optimization in the presence of demand response. Appl. Energy 2016, 162, 139-148. [CrossRef]

30. Govindan, K.; Shankar, K.M.; Kannan, D. Sustainable material selection for construction industry-A hybrid multi criteria decision making approach. Renew. Sustain. Energy Rev. 2016, 55, 1274-1288. [CrossRef]

31. Kumar, A.; Sah, B.; Singh, A.R.; Deng, Y.; He, X.; Kumar, P.; Bansal, R.C. A review of multi criteria decision making (MCDM) towards sustainable renewable energy development. Renew. Sustain. Energy Rev. 2017, 69, 596-609. [CrossRef]

32. Mardani, A.; Zavadskas, E.K.; Khalifah, Z.; Zakuan, N.; Jusoh, A.; Nor, K.M.; Khoshnoudi, M. A review of multi-criteria decision-making applications to solve energy management problems: Two decades from 1995 to 2015. Renew. Sustain. Energy Rev. 2017, 71, 216-256. [CrossRef]

33. Ananda, J.; Herath, G. A critical review of multi-criteria decision making methods with special reference to forest management and planning. Ecol. Econ. 2009, 68, 2535-2548. [CrossRef]

34. Vashishtha, S.; Ramachandran, M. Multicriteria evaluation of demand side management (DSM) implementation strategies in the Indian power sector. Energy 2006, 31, 2210-2225. [CrossRef]

35. Mokhtar, M.R.; Abdullah, M.P.; Hassan, M.Y.; Hussin, F. Combination of AHP-PROMETHEE and TOPSIS for selecting the best Demand Side Management (DSM) options. In Proceedings of the 2015 IEEE Student Conference on Research and Development (SCOReD), Kuala Lumpur, Malaysia, 13-14 December 2015; IEEE: Piscataway, NJ, USA, 2015; pp. 367-372.

36. Li, N.; Zhao, H. Performance evaluation of eco-industrial thermal power plants by using fuzzy GRA-VIKOR and combination weighting techniques. J. Clean. Prod. 2016, 135, 169-183. [CrossRef]

37. Lin, B.; Yang, L. The potential estimation and factor analysis of China's energy conservation on thermal power industry. Energy Policy 2013, 62, 354-362. [CrossRef]

38. Dong, J.; Huo, H.; Guo, S. Demand Side Management Performance Evaluation for Commercial Enterprises. Sustainability 2016, 8, 1041. [CrossRef]

39. Dong, J.; Huo, H.; Liu, D.; Li, R. Evaluating the Comprehensive Performance of Demand Response for Commercial Customers by Applying Combination Weighting Techniques and Fuzzy VIKOR Approach. Sustainability 2017, 9, 1332. [CrossRef]

40. Shemshadi, A.; Shirazi, H.; Toreihi, M.; Tarokh, M.J. A fuzzy VIKOR method for supplier selection based on entropy measure for objective weighting. Expert Syst. Appl. 2011, 38, 12160-12167. [CrossRef]

41. Zadeh, L.A. Probability measures of fuzzy events. J. Math. Anal. Appl. 1968, 23, 421-427. [CrossRef]

42. Girubha, R.J.; Vinodh, S. Application of fuzzy VIKOR and environmental impact analysis for material selection of an automotive component. Mater. Des. 2012, 37, 478-486. [CrossRef]

43. Alcan, P.; Balin, A.; Başligil, H. Fuzzy multicriteria selection among cogeneration systems: A real case application. Energy Build. 2013, 67, 624-634. [CrossRef]

44. Patil, S.K.; Kant, R. A hybrid approach based on fuzzy DEMATEL and FMCDM to predict success of knowledge management adoption in supply chain. Appl. Soft Comput. 2014, 18, 126-135. [CrossRef]

45. Delgado, M.; Herrera, F.; Herrera-Viedma, E.; Martinez, L. Combining numerical and linguistic information in group decision making. Inf. Sci. 1998, 107, 177-194. [CrossRef]

46. Opricovic, S. Multicriteria optimization of civil engineering systems. Fac. Civ. Eng. Belgrade 1998, 2, 5-21.

47. Chen, L.Y.; Wang, T.C. Optimizing partners' choice in IS/IT outsourcing projects: The strategic decision of fuzzy VIKOR. Int. J. Prod. Econ. 2009, 120, 233-242. [CrossRef]

48. Sanayei, A.; Mousavi, S.F.; Yazdankhah, A. Group decision making process for supplier selection with VIKOR under fuzzy environment. Expert Syst. Appl. 2010, 37, 24-30. [CrossRef]

49. Saaty, T.L. What is the analytic hierarchy process? In Mathematical Models for Decision Support; Springer: Berlin/Heidelberg, Germany, 1988; pp. 109-121.

50. Marsh, S. Facilitating and Training in Quality Function Deployment; GOAL/QPC: Methuen, MA, USA, 1991. 
51. Buckley, J.J. Fuzzy hierarchical analysis. Fuzzy Sets Syst. 1985, 17, 233-247. [CrossRef]

52. Zheng, G.; Zhu, N.; Tian, Z.; Chen, Y.; Sun, B. Application of a trapezoidal fuzzy AHP method for work safety evaluation and early warning rating of hot and humid environments. Saf. Sci. 2012, 50, 228-239. [CrossRef]

53. Junior, F.R.L.; Osiro, L.; Carpinetti, L.C.R. A comparison between Fuzzy AHP and Fuzzy TOPSIS methods to supplier selection. Appl. Soft Comput. 2014, 21, 194-209. [CrossRef]

54. Shannon, C.E.; Weaver, W. The Mathematical Theory of Communication; University of Illinois Press: Champaign, IL, USA, 1998.

55. Lihong, M.; Yanping, Z.; Zhiwei, Z. Improved VIKOR algorithm based on AHP and Shannon entropy in the selection of thermal power enterprise's coal suppliers. In Proceedings of the 2008 International Conference on Information Management, Innovation Management and Industrial Engineering, Taipei, Taiwan, 19-21 December 2008; IEEE: Piscataway, NJ, USA; Volume 2, pp. 129-133.

56. Wang, T.C.; Lee, H.D. Developing a fuzzy TOPSIS approach based on subjective weights and objective weights. Expert Syst. Appl. 2009, 36, 8980-8985. [CrossRef]

57. Godden, J.W.; Stahura, F.L.; Bajorath, J. Variability of molecular descriptors in compound databases revealed by Shannon entropy calculations. J. Chem. Inf. Comput. Sci. 2000, 40, 796-800. [CrossRef] [PubMed]

58. Lee, D.K.; Park, S.Y.; Park, S.U. Development of assessment model for demand-side management investment programs in Korea. Energy Policy 2007, 35, 5585-5590. [CrossRef]

59. Strbac, G. Demand side management: Benefits and challenges. Energy Policy 2008, 36, 4419-4426. [CrossRef]

60. Gyamfi, S.; Krumdieck, S.; Urmee, T. Residential peak electricity demand response-Highlights of some behavioural issues. Renew. Sustain. Energy Rev. 2013, 25, 71-77. [CrossRef]

61. Albadi, M.H.; El-Saadany, E.F. A summary of demand response in electricity markets. Electr. Power Syst. Res. 2008, 78, 1989-1996. [CrossRef]

62. Soares, A.; Gomes, Á.; Antunes, C.H. Categorization of residential electricity consumption as a basis for the assessment of the impacts of demand response actions. Renew. Sustain. Energy Rev. 2014, 30, 490-503. [CrossRef]

63. Feuerriegel, S.; Bodenbenner, P.; Neumann, D. Value and granularity of ICT and smart meter data in demand response systems. Energy Econ. 2016, 54, 1-10. [CrossRef]

64. Li, W.; Logenthiran, T.; Woo, W.L.; Phan, V.T.; Srinivasan, D. Implementation of demand side management of a smart home using multi-agent system. In Proceedings of the 2016 IEEE Congress on Evolutionary Computation (CEC), Vancouver, BC, Canada, 24-29 July 2016; IEEE: Piscataway, NJ, USA; pp. 2028-2035.

65. Siano, P. Demand response and smart grids-A survey. Renew. Sustain. Energy Rev. 2014, 30, 461-478. [CrossRef]

66. Conchado, A.; Linares, P.; Lago, O. Santamaría, A. An estimation of the economic and environmental benefits of a demand-response electricity program for Spain. Sustain. Prod. Consum. 2016, 8, 108-119. [CrossRef]

67. Peak Load Management Association (PLMA). Demand Response: Principles for Regulatory Guidance; Peak Load Management Association: Vallejo, CA, USA, 2002.

(c) 2018 by the authors. Licensee MDPI, Basel, Switzerland. This article is an open access article distributed under the terms and conditions of the Creative Commons Attribution (CC BY) license (http:/ / creativecommons.org/licenses/by/4.0/). 